Article

\title{
Control Strategies to Smooth Short-Term Power Fluctuations in Large Photovoltaic Plants Using Battery Storage Systems
}

\author{
Javier Marcos *, Iñigo de la Parra, Miguel García and Luis Marroyo \\ Department of Electrical and Electronic Engineering, Public University of Navarre (UPNa), \\ Campus Arrosadia s/n, Edificio de los Pinos, Pamplona 31006, Spain; \\ E-Mails: inigo.delaparra@unavarra.es (I.P.); miguel.garcía@unavarra.es (M.G.); \\ luisma@unavarra.es (L.M.) \\ * Author to whom correspondence should be addressed; E-Mail: javier.marcos@unavarra.es; \\ Tel.: +34-948-169-277; Fax: +34-948-169-884.
}

External Editor: Neville R. Watson

Received: 7 August 2014; in revised form: 15 September 2014 / Accepted: 30 September 2014 / Published: 16 October 2014

\begin{abstract}
The variations in irradiance produced by changes in cloud cover can cause rapid fluctuations in the power generated by large photovoltaic (PV) plants. As the PV power share in the grid increases, such fluctuations may adversely affect power quality and reliability. Thus, energy storage systems (ESS) are necessary in order to smooth power fluctuations below the maximum allowable. This article first proposes a new control strategy (step-control), to improve the results in relation to two state-of-the-art strategies, ramp-rate control and moving average. It also presents a method to quantify the storage capacity requirements according to the three different smoothing strategies and for different PV plant sizes. Finally, simulations shows that, although the moving-average (MA) strategy requires the smallest capacity, it presents more losses (2-3 times more) and produces a much higher number of cycles over the ESS (around 10 times more), making it unsuitable with storage technologies as lithium-ion. The step-control shown as a better option in scenery with exigent ramp restrictions (around $2 \% / \mathrm{min}$ ) and distributed generation against the ramp-rate control in all ESS key aspects: $20 \%$ less of capacity, up to $30 \%$ less of losses and a $40 \%$ less of ageing. All the simulations were based on real PV production data, taken every $5 \mathrm{~s}$ in the course of one year (2012) from a number of systems with power outputs ranging from $550 \mathrm{~kW}$ to $40 \mathrm{MW}$.
\end{abstract}


Keywords: grid-connected photovoltaic (PV) plants; power fluctuations smoothing; control strategies; energy storage sizing

\section{Introduction}

The concern shown by a number of transmission system operators (TSO) over the increasing presence of large photovoltaic (PV) plants is leading to constant changes in grid codes, directed at facilitating PV penetration yet without detracting from the safety and quality of supply. The main reason is the fluctuating nature of PV generation due to variations in irradiance as a result of changes in cloud cover. Specifically, for very fast fluctuations, the TSO has an extremely limited response capacity and, if the fluctuations exceed the permitted limits, then there is a risk of a complete power system failure. In fact, some countries are currently working on grid codes that take this problem into account [1-3]. This risk is particularly significant for high PV penetration rates, such as islands. For example, the Puerto Rico Electric Power Authority [1] requires the PV plant fluctuations to be less than $10 \% / \mathrm{min}$. In other countries such as Mexico, the regulations target greater restrictions, of around $1 \% / \mathrm{min}-5 \% / \mathrm{min}[2]$. The speed and magnitude of these fluctuations are well-known and have been quantified not only with irradiance data [4-9] but also with power output measurements [10-12]. Likewise, the researchers $[5,13,14]$ have demonstrated that the larger the PV system is, the lower the PV fluctuations are: typically, for this $1 \mathrm{~min}$ time window, a $1 \mathrm{MWp}$ PV plant records fluctuations of up to $90 \%$, a $9.5 \mathrm{MWp}$ plant easily exceeds 70\% [14], whilst a $45.6 \mathrm{MWp}$ fluctuates by up to 33\% [15]. Therefore, as these new regulations gradually come into force, it will be necessary to equip PV plants with an energy storage system (ESS) in order to smooth out any fluctuations to within the maximum limits.

Logically, the installation of an ESS has a major impact on the energy/economic balance of the PV system, playing a key role in the viability of the future PV systems due to their high costs and reduced shelf life. As a result, parameters such as energy capacity, losses and the cycling degradation of the ESS, take on particular importance. Any reduction in both the ESS capacity required and charge/discharge cycles will have a positive impact on reducing the investment required to install and maintain the ESS. Consequently, the control strategy selected in order to smoothing fluctuations will be a crucial decision. Nevertheless, given the maximum fluctuation limitation, there is a range of control strategies to reduce the fluctuations to under this limit. At present, the two most often proposed strategies in the literature are ramp-rate control [16-21] and the moving-average (MA) [22-25]. The main advantage of MA is that, if the system is equipped with an ideal converter and battery, by definition of the mean value, the value of the energy in the ESS at the beginning and end of any given day should be the same. In real practice, at the end of the day, the battery is discharged to a value equal to the energy lost in the charging/discharging processes. On the other hand, the key point of the ramp-rate control is that only acts when the fluctuation exceeds the maximum allowable ramp-rate value (i.e., lower degradation). There are also other strategies available such as the constant production strategy [26,27], however, this goes beyond smoothing out the fluctuations in short periods of time and requires a much larger ESS. Even so, no individual analysis is made for each of these 
two strategies as to the impact of them on the actual ESS requirements: energy capacity; charge/discharge cycles; cycling degradation; losses in the power electronic converter (PEC); losses in the ESS, etc. Only Marcos et al. [15] propose a method for sizing the ESS (with regard to power output and energy), but exclusively for ramp control. Accordingly, few comparisons have been made between the performance of the strategies ramp-rate control and the moving average working in the same PV plant-ESS system. The studies conducted are primarily focused on programming, monitoring and implementing the strategy [22,28-30].

Likewise, these two strategies do not take into account a well-known smoothing effect over the fluctuations derived from the dispersion of PV plants: in a scenario of distributed generation, short-term power fluctuations of a group of PV plants are reduced linearly by the square root of the number of plants $[5,31,32]$. With the goal of take advantage of this natural behavior, we first propose a novel control strategy (step-control) to improve the results in relation to the state-of-the-art strategies, ramp-rate control and MA, in terms of the performance and cyclability of the ESS. Secondly, we describes the method in order to calculate, for any PV plant size and maximum allowable ramp-rate, the energy storage requirements for both MA and step-control strategies. Finally, we have compared these three control methods in order to fit the grid quality demands. Each control method is evaluated regarding the quality of produced signal and the demand on the ESS. All the simulations were based on actual PV production data, taken every $5 \mathrm{~s}$ in the course of one year (2012) from a number of systems with power outputs ranging from $550 \mathrm{~kW}$ to $40 \mathrm{MW}$. The experimental ESS comprised a lithium-ion battery connected at the AC side through a two-way DC/AC PEC. The results shown can be used as a guide to select the best control strategy, and the optimum design and selection of the ESS, making it possible to assess the impact of the ESS on the PV plant energy/economic balance.

\section{Database}

Thanks to extensive monitoring, $5 \mathrm{~s}$ synchronized records of the output power of all the inverters from the Amaraleja (South Portugal, 38.1900 N, 7.2108 W) PV plant are available from May 2010. This plant, the property of Acciona Energía S.A. (Sarriguren, Spain), occupies an area of $250 \mathrm{Ha}$ and includes 2520 solar trackers with a rated output of $17.7-18.8 \mathrm{kWp}$, up to a total peak power of 45.6 MWp (inverter power, $P^{*}$, is $38.5 \mathrm{MW}$ ). Each tracker is tilted at an angle of $45^{\circ}$ in relation to the ground with vertical tracking in an east-west direction (azimuthal). The plant is divided into 70 units, each comprising 36 tracking systems connected to a $550 \mathrm{~kW}$ DC/AC inverter. The minimum and maximum distances between the units are $220 \mathrm{~m}$ and $2.5 \mathrm{~km}$, respectively. From this work, data was taken not only of the entire PV plant but also of five sections with $P^{*}$ between $0.55 \mathrm{~kW}$ and $11.5 \mathrm{MW}$ (Figure 1), making it possible to study the relationship between the storage requirements and the size of the PV power plant. The simulations presented in this paper are based on data recorded over the course of one year (2012). 
Figure 1. Field distribution of the Amaraleja photovoltaic (PV) plant sections considered in this paper.

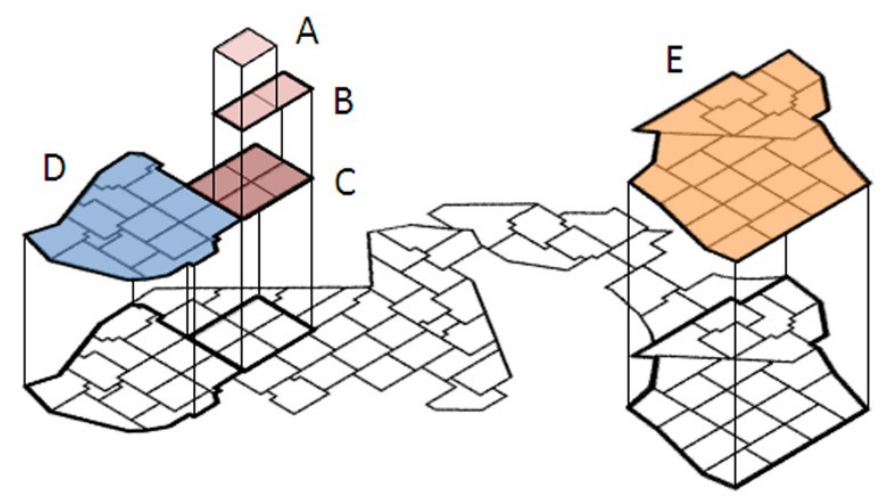

Section A: $0.55 \mathrm{MW}$

Section B: $1.1 \mathrm{MW}$

Section C: $2.2 \mathrm{MW}$

Section D: $6.6 \mathrm{MW}$

Section E: $11.5 \mathrm{MW}$

PV plant: $38.5 \mathrm{MW}$

\section{Power Fluctuations with No Energy Storage}

Power fluctuation $\Delta P_{\Delta t}(t)$ is defined at moment $t$ for a given sampling period, $\Delta t$, as the difference between two consecutive samples of the power generated $P \operatorname{PV}(t)$, normalized to the rated power of inverter $P^{*}$ of the plant in question, Equation (1), which is:

$$
\Delta P_{\Delta t}(t)=\frac{\left[P_{\mathrm{PV}}(t)-P_{\mathrm{PV}}(t-\Delta t)\right]}{P^{*}} \times 100
$$

Therefore, given a power output time series $\operatorname{Ppv}(t)$ as recorded in our experiment, it is possible to calculate an associated time series of fluctuations $\Delta P_{\Delta t}(t)$; resulting from applying Equation (1) with a given time window $\Delta t$ and moving it at the same rate as the monitoring resolution ( $5 \mathrm{~s}$ in our case). Having obtained vector $\Delta P_{\Delta t}(t)$, it is then possible to determine the amount of time the fluctuations exceed a given permitted maximum ramp value in the course of one year. This result can be seen in Figure 2, showing the frequency of occurrence of fluctuations greater than a certain ramp $r$ max, in relation to the total production time for one whole year (2012). As was to be expected, significant fluctuations decrease as $r_{\max }$ increases. For example, for a restriction such as [2], where $r_{\max }$ is equal to $2 \% / \mathrm{min}$, even for the 38.5 MW PV system, more than $10 \%$ of the total production time exceeds the maximum ramp condition. This example shows that a battery would be required in order to comply with any power ramp limits imposed. 
Figure 2. Frequency over one year (2012) of PV power fluctuations calculated in 1-min time window, $\Delta P_{1 \min }(t)$, are higher than a given $\operatorname{ramp} r(\% / \mathrm{min})$. The frequency value is given in relative terms to the total production time $(4380 \mathrm{~h})$.

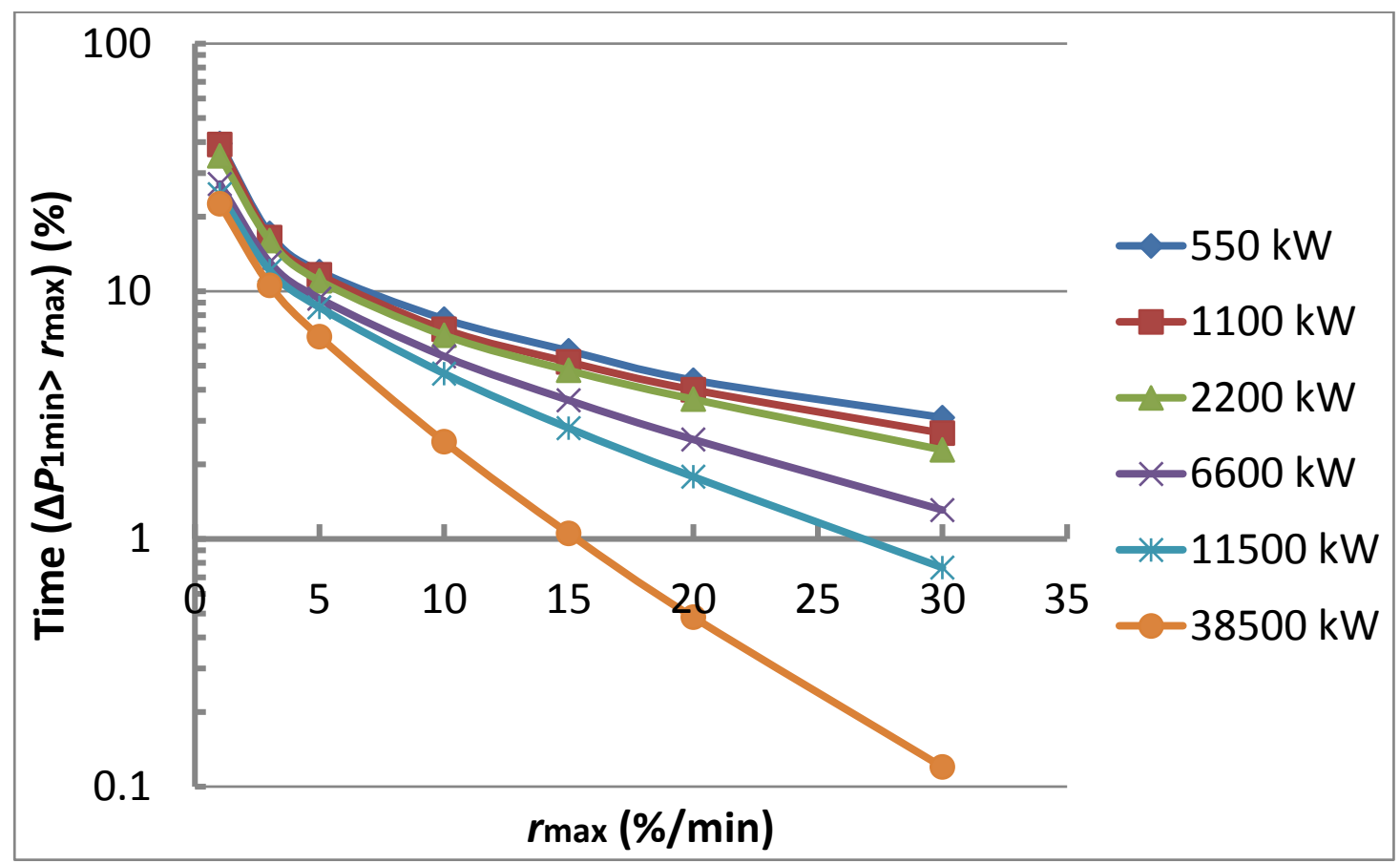

\section{A Generic Strategy for Smoothing Fluctuations through Energy Storage}

For our simulations, a lithium ion battery-based storage system was selected. Logically, the methodology put forward is equally valid for any other type of storage system (such as supercapacitors, flow batteries, fly wheels, etc.). Figure 3 shows the model used to simulate a generic strategy to smooth out fluctuations. For each sampling period, the algorithm reduces the fluctuations of $P \operatorname{Pv}(t)$ to the maximum permitted level $r_{\max }$ and the result is the power injected into the grid, $P_{\mathrm{G}}(t)$. The difference between $P_{\mathrm{G}}(t)$ and $P_{\mathrm{PV}}(t)$ is the power setpoint to either be provided by $\left(P_{\mathrm{ESS}}>0\right)$ or to be absorbed by the ESS $\left(P_{\text {ESS }}<0\right)$. The next step is to apply the performance of the PEC $\eta$ PEC and that of the lithium ion battery, $\eta_{\mathrm{BAT}}$, in order to obtain the battery power value $P_{\mathrm{BAT}}$ required.

Figure 3. Generic model for the evaluation of the fluctuation smoothing strategies at a PV plant with energy storage. As can be seen, the performance of the energy storage system (ESS) has been divided into two: on the one hand, the performance of the power converter (

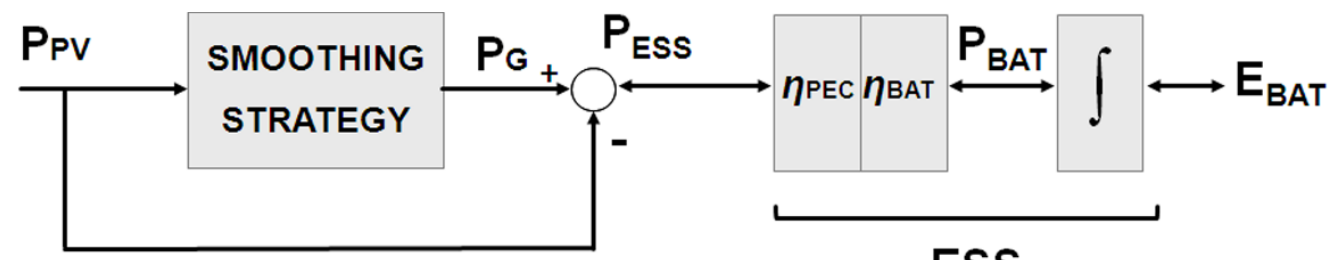

ESS

To calculate the PEC losses, a real curve obtained from the Ingecon Sun Powermax ${ }^{\circledR} 1$ MW [33] commercial converter was used, Figure 4. This same converter is connected to a $1 \mathrm{MW}$ transformer on 
the AC side, whose performance curve is also shown in Figure 4, together with the total for the PEC (Ingecon Sun + Transformer). With regard to the lithium ion battery losses, data was used from the manufacturer's catalogue, specifically the $1 \mathrm{MW} / 560 \mathrm{~kW} \cdot \mathrm{h}$ Intensium ${ }^{\circledR}$ Max battery made by SAFT (Bagnolet, France), whose round-trip efficiency can be considered constant and equal to 95\% [34]. The integral of $P_{\mathrm{BAT}}$ is the energy $E_{\mathrm{BAT}}$ to be provided by the battery in order to smooth the fluctuations. We would emphasize that this paper does not seek to achieve the accurate modelling of the performance of the ESS, but rather to make a comparison of the different strategies.

Figure 4. Power electronic converter (PEC) efficiency curve (reversible DC/AC converter, corresponding to the commercial converter INGECON SUN POWERMAX ${ }^{\circledR} 1 \mathrm{MW}$ plus $1 \mathrm{MW}$ transformer).

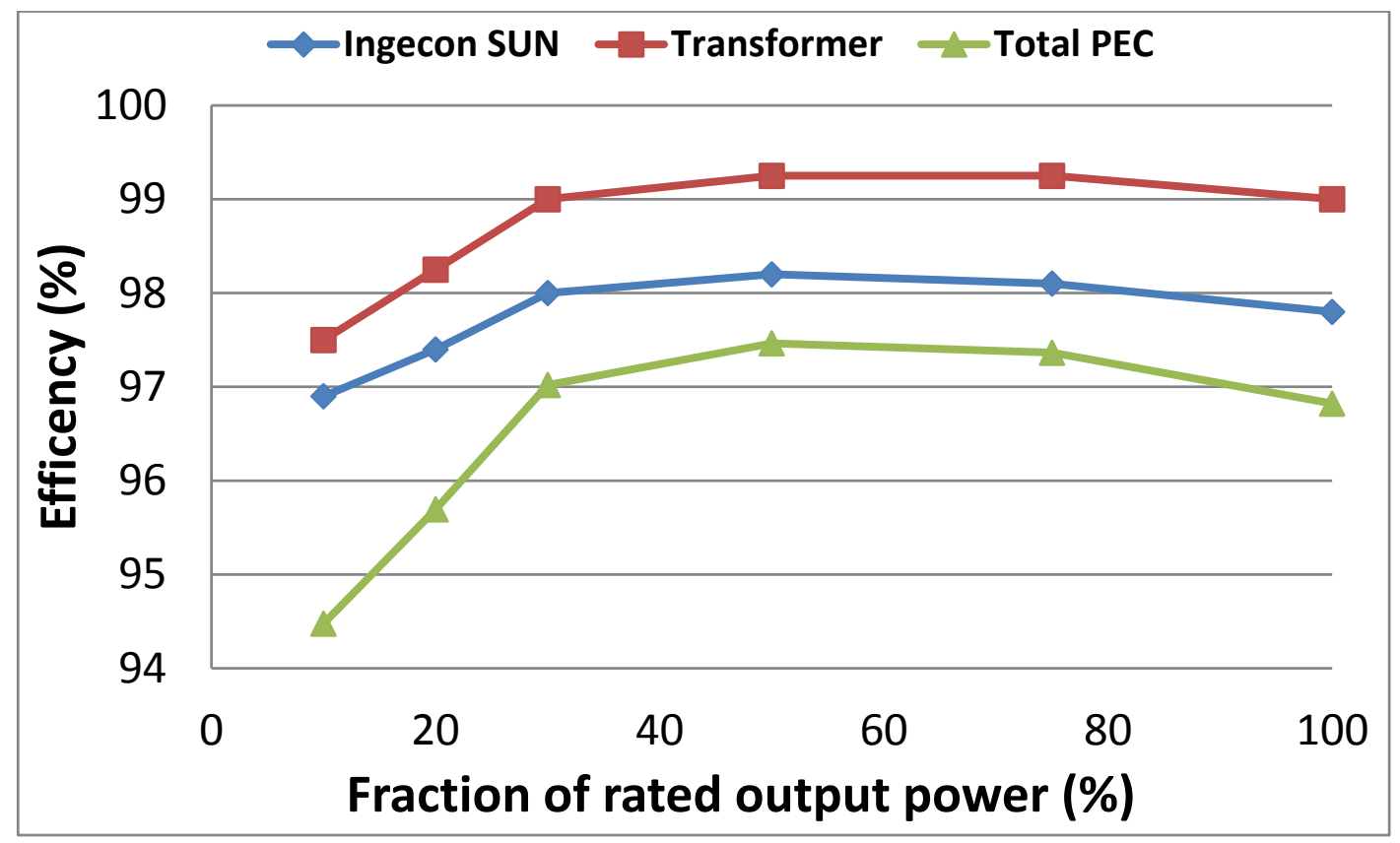

\subsection{Ramp Control Strategy}

Given a maximum allowable ramp condition for the power injected $r_{\max }$, at each simulation step $t$ the inverter tries to inject all the power to the grid, that is $P_{\mathrm{G}}(t)=P_{\mathrm{PV}}(t)$. The control is enabled if the difference with the previous sample $P_{\mathrm{G}}(t-\Delta t)$ exceeds the maximum ramp condition, that is, Equation (2):

$$
\left[P_{\mathrm{G}}(t-\Delta t)-\Delta t \cdot r_{\max }\right]>P_{\mathrm{G}}>\left[P_{\mathrm{G}}(t-\Delta t)+\Delta t \cdot r_{\max }\right]
$$

where $r_{\max }$ is expressed in units of power by time. This control has been improved by a state of charge (SOC) control proposed by [15] which prevents the natural tendency of the battery to discharge due to the effect of successive fluctuations (Figure 5). In this way, it is possible to maintain $E_{B A T}$ around the

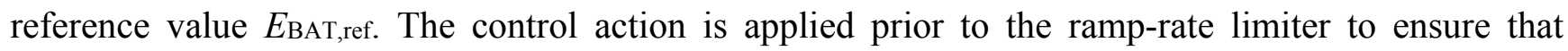
condition $r_{\max }$ is met at all times. For our simulations, we will work with $K=6$, a value which allows a good trade-off between speed and stability. Lower values might increase the risk of a complete discharge of $C_{\mathrm{BAT}}$, while higher values would result in extensive ESS usage. $K$ values between 2 and 8

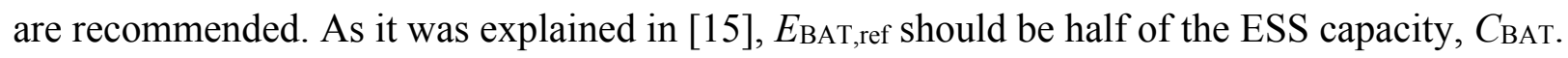


Figure 5. Ramp-rate control model modified with additional state of charge (SOC) control.

Note that the SOC control action is also smoothed by the ramp-limiter in order to guarantee that power fluctuations are always below $r_{\max }$.

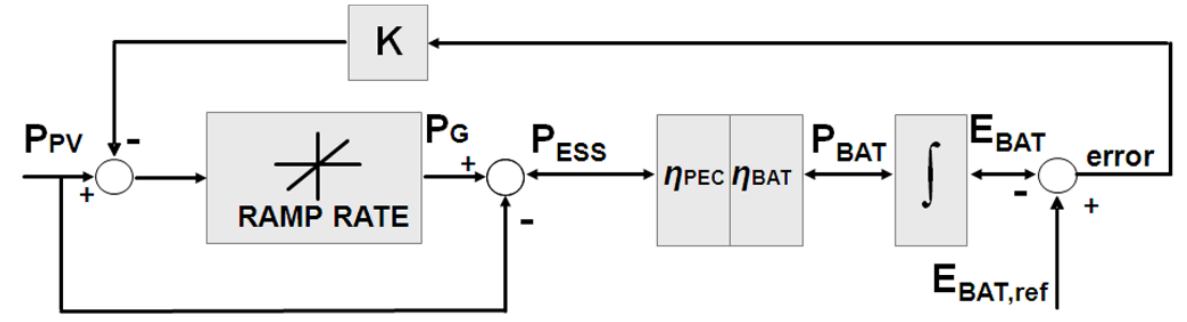

That previous work also proposed a model to determine $C_{\mathrm{BAT}}$ (Figure 6): basically, the worst fluctuation for a PV plant can be modelled as the response of a first order system with a time constant $\tau$ in relation to a $90 \%$ irradiance fluctuation $G(t)$ (global irradiance to diffuse irradiance).

Figure 6. Worst fluctuation model. The blue line represents the $P_{\mathrm{PV}}(t)$ response to an irradiance fluctuation (yellow line) and the red one is the power injected to the grid $P_{\mathrm{G}}$ with a ramp-rate control. The difference between $P_{\mathrm{G}}$ and $P_{\mathrm{PV}}$ is $P_{\mathrm{BAT}}$, the maximum difference corresponds to $P_{\mathrm{BAT}, \mathrm{MAX}}$ and the defined integral of $P_{\mathrm{BAT}}$ corresponds to $E_{\mathrm{BAT}, \mathrm{MAX}}$.

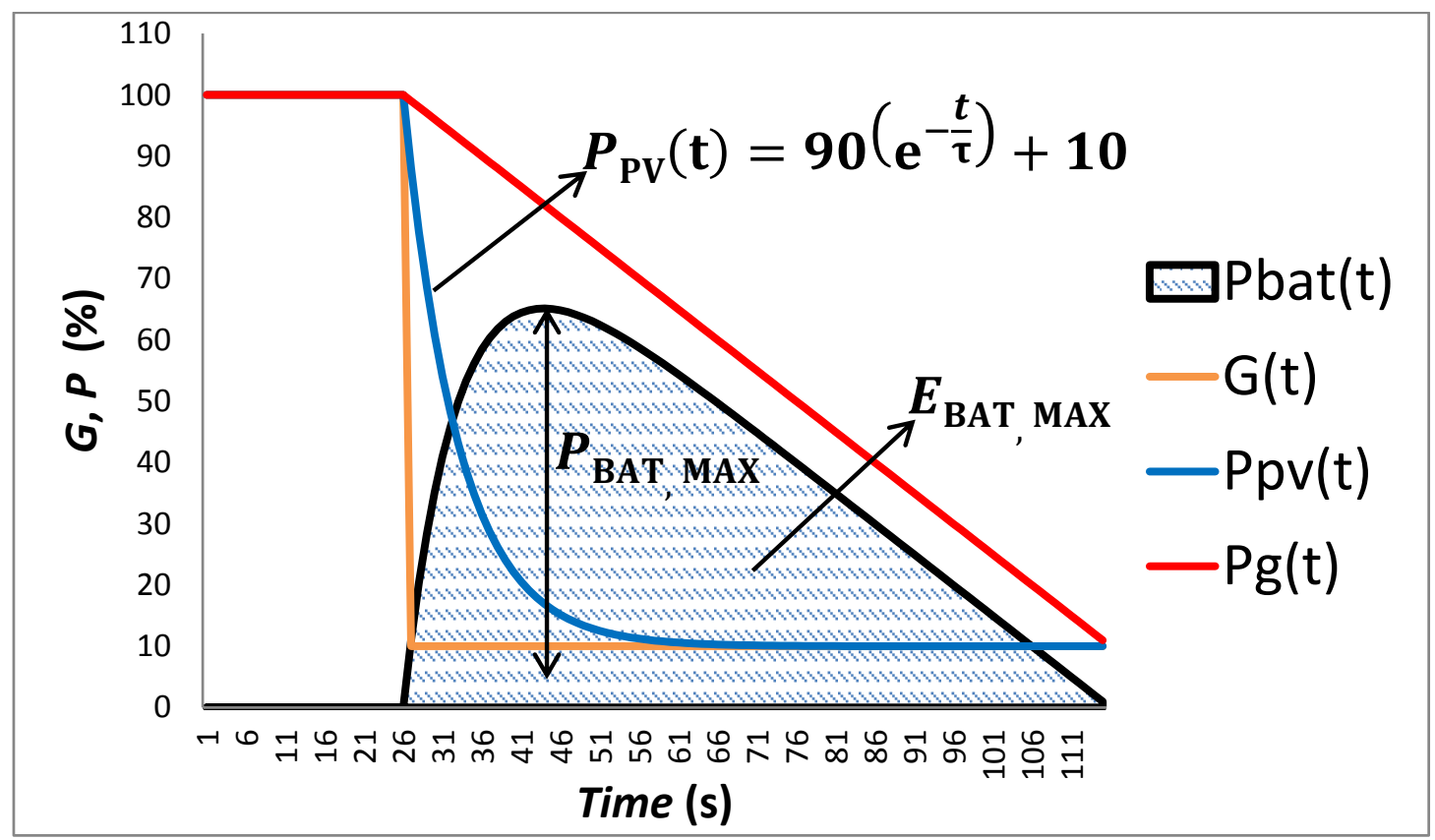

Furthermore, $\tau$ is dependent on the size of the PV plant $\left(P^{*}\right)$. Then, the energy required $E_{\mathrm{BAT}, \text { ramp }}$ to smooth the worst fluctuation with the ramp-rate control strategy is equal to the integral of the difference between $P_{\mathrm{PV}}(t)$ and $P_{\mathrm{G}, \mathrm{ramp}}(t)$, in other words, Equation (3):

$$
E_{\text {BAT,ramp }}=\frac{0.9 P *}{3600}\left[\frac{90}{2 \cdot r_{\max }}-\tau\right]
$$

where $P^{*}$ is expressed in $(\mathrm{kW}), r_{\max }$ in $(\% / \mathrm{s}), \tau$ in $(\mathrm{s})$, and $E_{\mathrm{BAT}, \text { ramp }}$ in $(\mathrm{kW} \cdot \mathrm{h})$. Furthermore, as the sign of the first fluctuation (positive or negative) is unknown, battery $C_{\mathrm{BAT}}$,ramp must be sized for double this power, Equation (4): 


$$
C_{\mathrm{BAT}, \text { ramp }}=2 \cdot E_{\mathrm{BAT}, \mathrm{ramp}}=\frac{1.8 P^{*}}{3600}\left[\frac{90}{2 \cdot r_{\max }}-\tau\right]
$$

where $P^{*}$ is expressed in $(\mathrm{kW}), r_{\max }$ in $(\% / \mathrm{s}), \tau$ in $(\mathrm{s})$, and $C_{\mathrm{BAT}, \mathrm{ramp}}$ in $(\mathrm{kW} \cdot \mathrm{h})$.

Figure 7a shows, for 15 February 2012, the evolution of the power generated $P_{\mathrm{PV}}$ of Section B $(1100 \mathrm{~kW})$ and the simulated power output that would be injected to grid $P_{\mathrm{G}}$ through this algorithm for $r_{\max }=2 \% / \mathrm{min}$, a similar restriction to that of [2]. According to Equation (4), $C_{\mathrm{BAT}}$ needed to smooth the worst fluctuation is equal to $746 \mathrm{~kW} \cdot \mathrm{h}$, so $E_{\mathrm{BAT} \text {,ref }}=373 \mathrm{~kW} \cdot \mathrm{h}$. Figure $7 \mathrm{~b}$ plots the corresponding $P_{B A T}$ for that specific day, whilst Figure $7 \mathrm{c}$ plots the integral over time $E_{\text {BAT. }}$ It can be seen how the SOC control operates correctly, returning the battery energy to its initial state. For this day, the required battery power is $P_{\mathrm{BAT}, \mathrm{MAX}}=937 \mathrm{~kW}$ (or $P_{\mathrm{BAT}, \mathrm{MAX}}=0.85 \cdot P^{*}$ ) and the required effective storage capacity is $C_{\mathrm{BAT}}=E_{\mathrm{BAT}, \mathrm{MAX}}-E_{\mathrm{BAT}, \mathrm{MIN}}=433 \mathrm{~kW} \cdot \mathrm{h}$ (or $23 \mathrm{~min}$ of capacity, equivalent to $0.39 \mathrm{~h}$ of $\mathrm{PV}$ plant production at $P^{*}$ ). The total energy that has passed through the battery is $1600 \mathrm{~kW} \cdot \mathrm{h}$, equivalent to $54 \%$ of daily production, whilst the total losses (battery plus PEC) are $3.87 \%$ of production.

Figure 7. (a) Evolution of the generated power, $P_{\mathrm{PV}}(t)$ on 15 February 2012 by Section $\mathrm{B}$ and the simulated power that would have been injected to the grid $P_{\mathrm{G}}(t)$ if a battery had been available to limit fluctuations to $r_{\max }$ of $2 \% / \mathrm{min}(0.166 \% / 5 \mathrm{~s})$; $(\mathbf{b})$ battery power, $P_{\mathrm{BAT}}$; and (c) battery energy, $E_{\mathrm{BAT}}$. The simulation has been made based on the model shown in Figure 5.

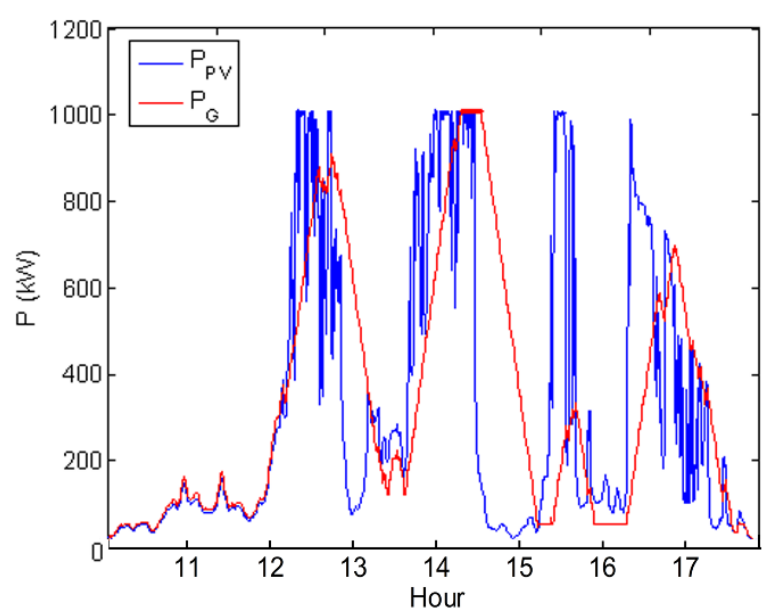

(a)

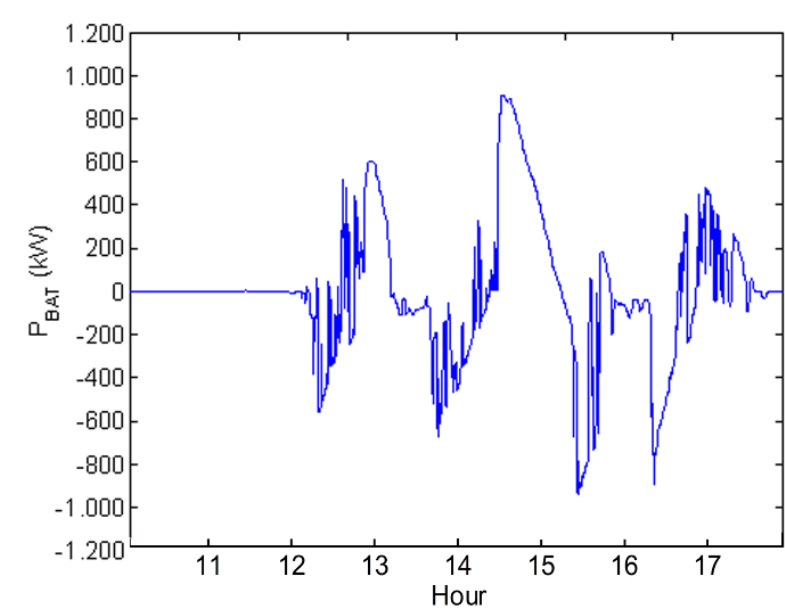

(b)

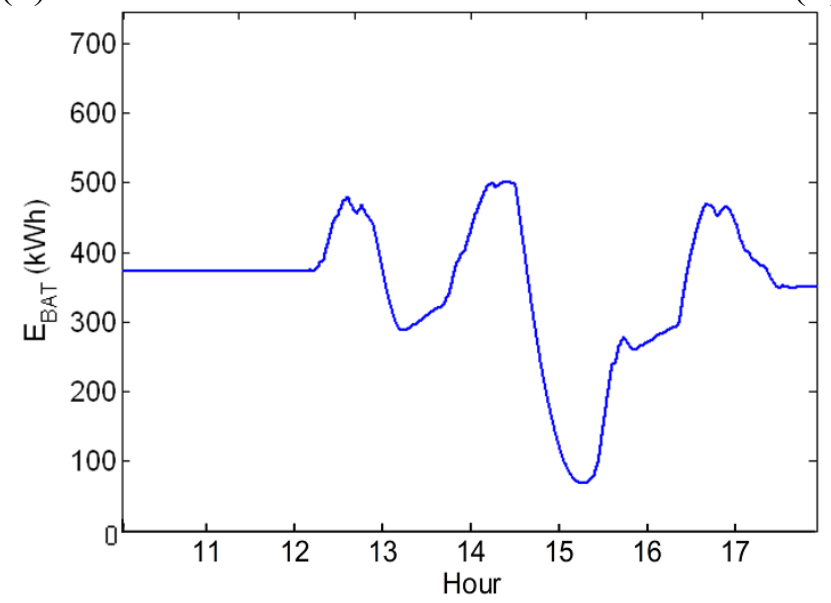

(c) 


\subsection{Moving-Average Strategy}

Given a power time series $P \operatorname{PV}(t)$ as recorded in our experiment, the power smoothed to be injected into the grid $P_{\mathrm{G}}(t)$ is calculated as the mean production value in a time window with a duration of $T$, in other words, Equation (5):

$$
P_{\mathrm{G}}(t)=\frac{1}{T} \int_{t-T}^{t} P_{\mathrm{PV}}(t) \mathrm{d} t
$$

The greater the time for window $T$, the greater the smoothing of the fluctuations at $P_{\mathrm{G}}(t)$. The key advantage of this strategy is that, if the system is equipped with an ideal converter and battery $\left(\eta_{\mathrm{BAT}}=\eta_{\mathrm{PEC}}=1\right)$, by definition of the mean value, the value of $E_{B A T}$ at the beginning and end of any given day should be the same. Therefore, there is no need for any type of SOC control to prevent the continuous battery discharge. However, if $\eta_{\text {BAT }}$ and $\eta_{\mathrm{PEC}}<1$, then this advantage disappears and, at the end of the day, the battery is discharged to a value equal to the energy lost in the charging/discharging processes in the ESS. This same phenomenon was already observed in [35]. This paper proposes a simple solution to this problem, consisting in offsetting the mean value of the losses, also for a time window $T$ (Figure 8).

Figure 8. Model of the moving-average (MA) strategy, offsetting the ESS losses.

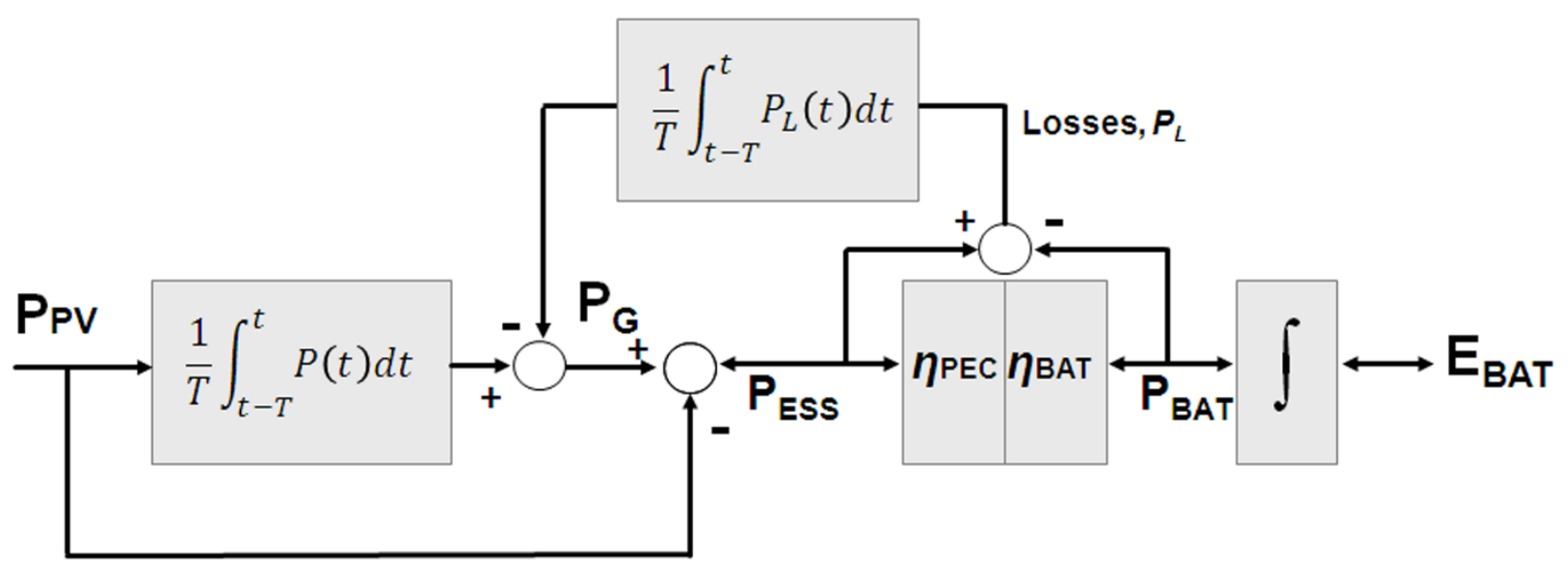

In the same manner as was done in ramp-rate control, it would be important to obtain a general expression to determine the storage capacity needed by the MA strategy. Figure 9 yet again resolves this problem. The analytical expression of function $P_{\mathrm{G}, \mathrm{MA}}$ is equal to Equation (6):

$$
P_{\mathrm{G}, \mathrm{MA}}(t)=\frac{1}{T} \int_{t-T}^{t} P_{\mathrm{PV}}(t) \mathrm{d} t=\frac{1}{T} \int_{t-T}^{t}\left[90\left(\mathrm{e}^{-t / \tau}\right)+10\right] \mathrm{d} t
$$

Substituting $T=5400 / r$ and resolving Equation (6), we obtain the general expression of $P_{\mathrm{G}, \mathrm{MA}}$, Equation (7):

$$
P_{\mathrm{G}, \mathrm{MA}}(t)=100-\frac{90}{5400}\left[t r-\tau\left(\frac{1}{\mathrm{e}^{t / \tau}}-1\right)\right]
$$

The final term of this expression is responsible for the phase lag existing between $P_{\mathrm{G}, \mathrm{MA}}$ and $P_{\mathrm{G}, \mathrm{ramp}}$ which can be seen in Figure 9 . The area between both curves $A_{\mathrm{MA} \text {,ramp }}$ can approximately be calculated by Equation (8): 


$$
A_{\mathrm{MA}, \mathrm{ramp}}=\frac{1.5 P^{*}}{6000} \tau \sqrt{r^{2}+1} \operatorname{sen}\left[90^{\circ}-\operatorname{tg}^{-1}(r)\right]
$$

where $P^{*}$ is expressed in $(\mathrm{kW}), r_{\max }$ in $(\% / \mathrm{min}), \tau$ in $(\mathrm{s})$, and $A_{\mathrm{MA}, \text { ramp }}$ in $(\mathrm{kW} \cdot \mathrm{h})$. Therefore, the MA strategy requires a battery equal to Equation (9):

$$
C_{\mathrm{BAT}, \mathrm{MA}}=E_{\mathrm{BAT}, \mathrm{ramp}}+A_{\mathrm{MA}, \mathrm{ramp}}
$$

Figure 9. Model to calculate the storage capacity needed $C_{\mathrm{BAT}, \mathrm{MA}}$ for the MA strategy.

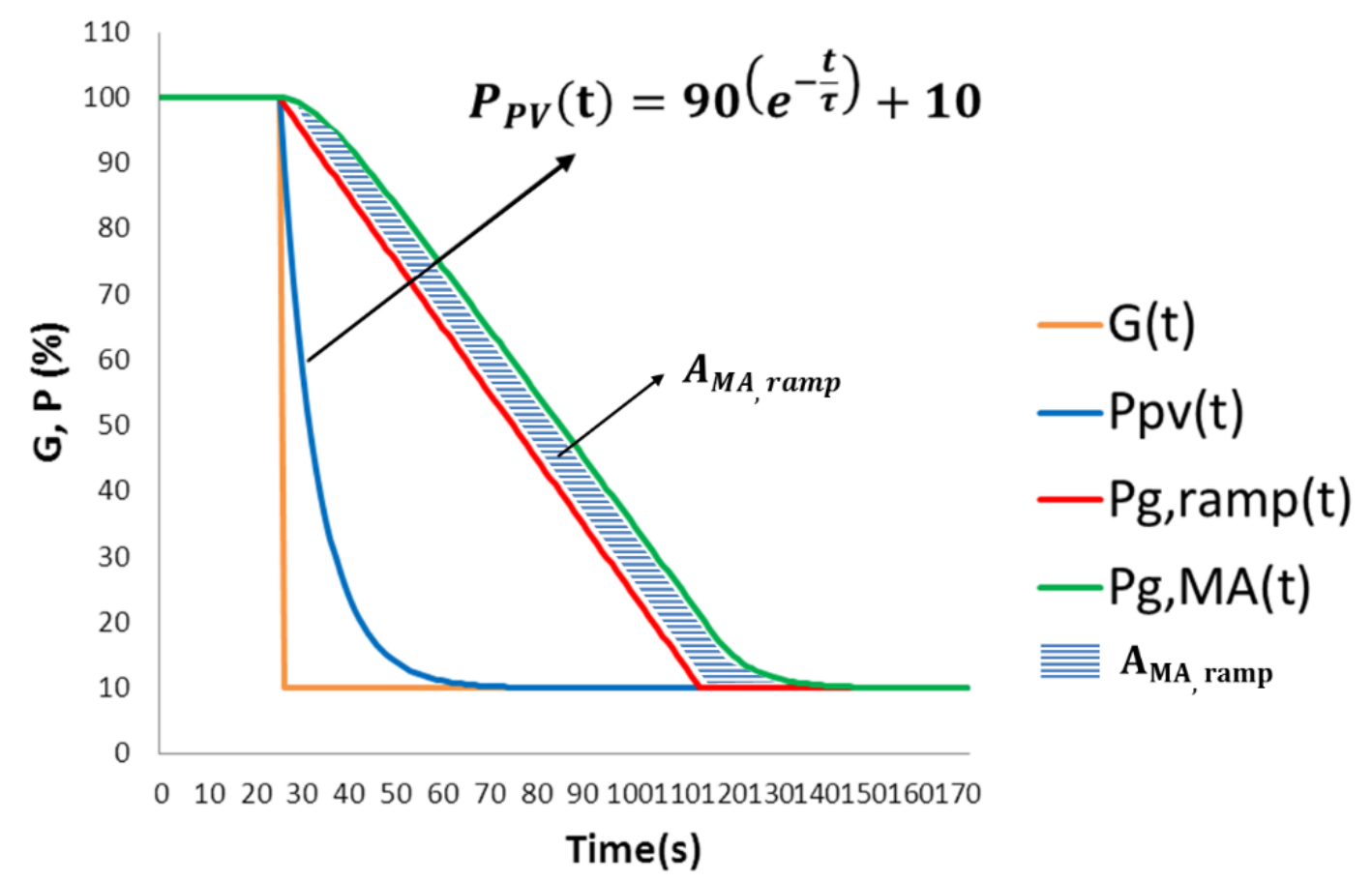

For example, for $P^{*}=1.1 \mathrm{MW}(\tau=6.14 \mathrm{~s})$ and $r_{\max }=2 \% / \mathrm{min}$, Equation (3) provides $E_{\mathrm{BAT}, \mathrm{ramp}}=370 \mathrm{~kW} \cdot \mathrm{h}$ and $A_{\mathrm{MA}, \mathrm{ramp}}=1.8 \mathrm{~kW} \cdot \mathrm{h}$, then $C_{\mathrm{BAT}, \mathrm{MA}}=371 \mathrm{~kW} \cdot \mathrm{h}$, equivalent to $0.35 \mathrm{~h}$ of $\mathrm{PV}$ plant production at $P^{*}$. For the same ramp restriction and $P^{*}=38.5 \mathrm{MW}(\tau=75 \mathrm{~s})$, Equation (3) gives $E_{\mathrm{BAT} \text {,ramp }}=12,995 \mathrm{~kW} \cdot \mathrm{h}$ and $A_{\mathrm{MA}, \text { ramp }}=715 \mathrm{~kW} \cdot \mathrm{h}$, then $C_{\mathrm{BAT}, \mathrm{MA}}=13,710 \mathrm{~kW} \cdot \mathrm{h}$, equivalent to $0.36 \mathrm{~h}$ of PV plant production at $P^{*}$.

Figure 10 shows the example of applying this strategy once again for 15 February 2012, and with $T=2700 \mathrm{~s}$. For this time window $T$, the maximum daily fluctuation in $1 \mathrm{~min}$, is reduced to $1.95 \% / \mathrm{min}$. For this strategy, the required battery power is $P_{\mathrm{BAT}, \mathrm{MAX}}=919 \mathrm{~kW}$ (or $P_{\mathrm{BAT}, \mathrm{MAX}}=0.83 \cdot P^{*}$ ) and the required effective battery capacity is $C_{\mathrm{BAT}}=E_{\mathrm{BAT}, \mathrm{MAX}}-E_{\mathrm{BAT}, \mathrm{MIN}}=378 \mathrm{~kW} \cdot \mathrm{h}$ (or $20 \mathrm{~min}$ of capacity, equivalent to $0.34 \mathrm{~h}$ of $\mathrm{PV}$ plant production at $P^{*}$ ). We would emphasise that the SOC control tends to return the battery power to its original state, thanks to the offsetting of losses. Likewise, although $P_{\mathrm{G}}$ is slightly smoother than in the case of ramp-rate control, the ESS endures a few more cycles. The total energy that has passed through the battery is $2052 \mathrm{~kW} \cdot \mathrm{h}$, equivalent to $70 \%$ of daily production, whilst the total losses in the battery and PEC are $5.2 \%$ of production. 
Figure 10. (a) Evolution of the generated power, $P \operatorname{Pv}(t)$ on 15 February 2012 by Section B $(1.1 \mathrm{MW})$ and the simulated power which would be injected to the grid $P_{\mathrm{G}}(t)$ under the moving average strategy $(T=2700 \mathrm{~s})$; (b) battery power, $P_{\mathrm{BAT}}$; and (c) battery energy, $E_{\mathrm{BAT}}$. The simulation has been made based on the model shown in Figure 8.

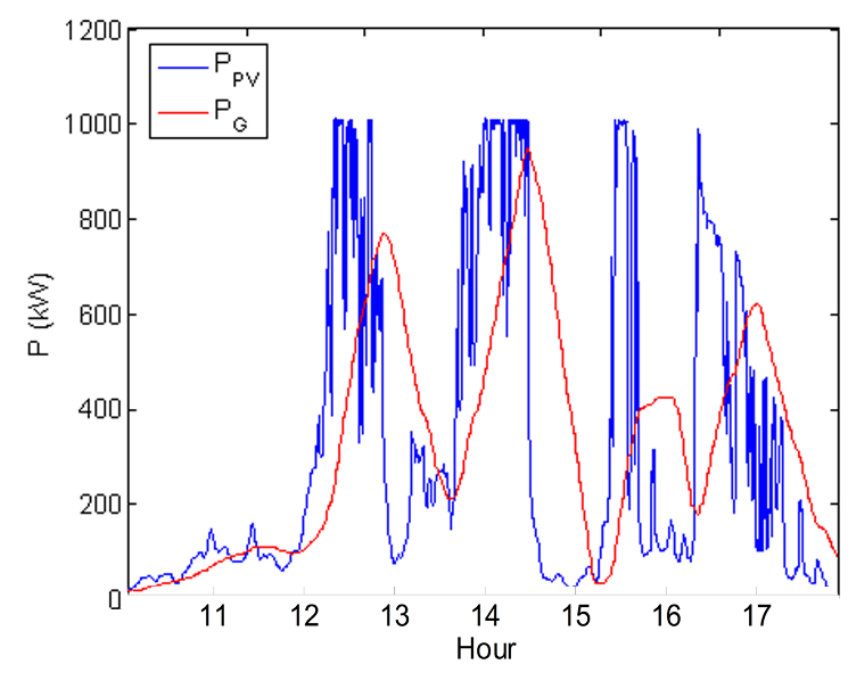

(a)

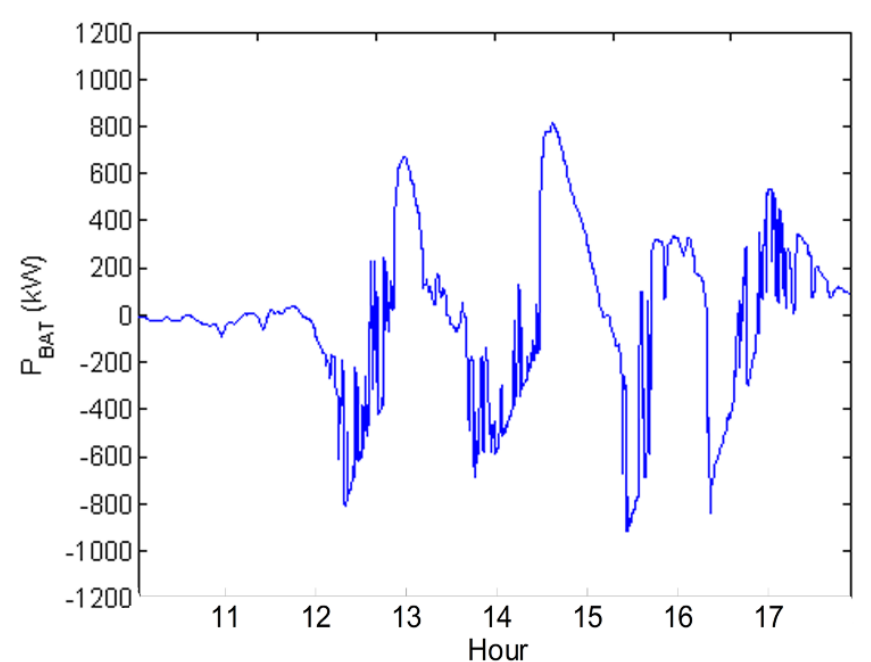

(b)

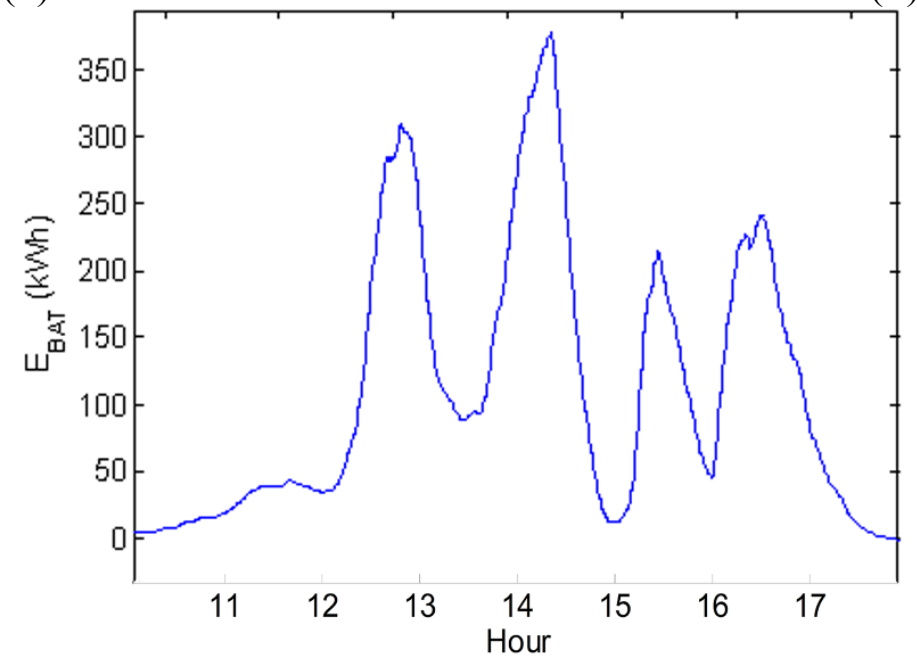

(c)

We should emphasize that this strategy must be operative even on clear days, because the reduction in fluctuations must be ensured in all cases. As will be shown later, this will cause an excessive cycling in the ESS. Figure 11 shows the example of applying this strategy during a clear day. In the absence of methods of predicting fluctuations, the MA must be applied since sunrise, preparing for a potential fluctuation that does not happen. As a result, the ESS suffered one charge-discharge cycle unnecessarily (Figure 11c). 
Figure 11. (a) Evolution of the generated power, $P \operatorname{Pv}(t)$ during a clear sky day, 10 August 2011 by Section B (1.1 MW) and the simulated power which would be injected to the grid $P_{\mathrm{G}}(t)$ under the moving average strategy $(T=2700 \mathrm{~s})$; (b) battery power, $P_{\mathrm{BAT}}$; and (c) battery energy, EBAT.

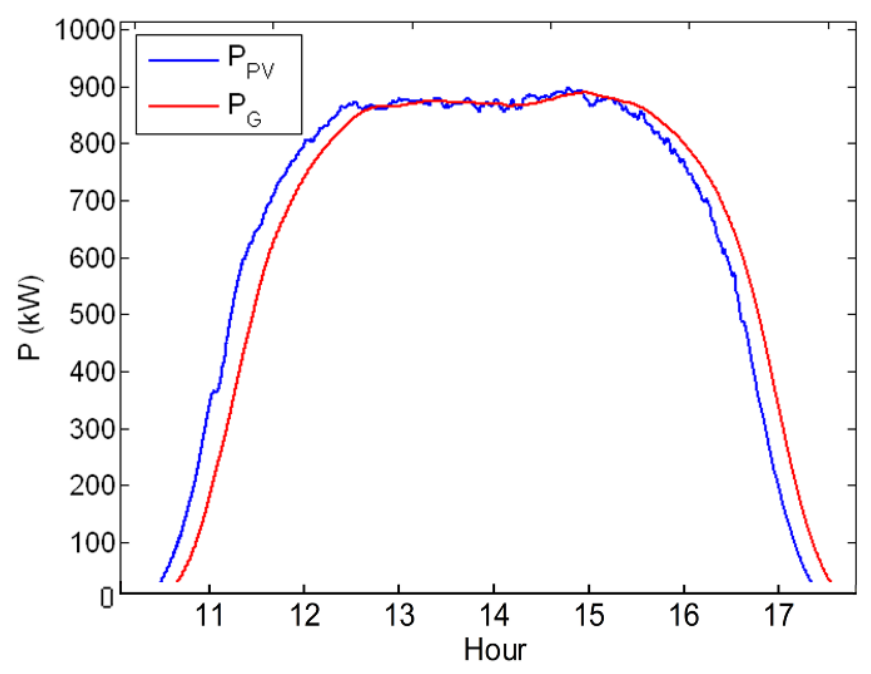

(a)

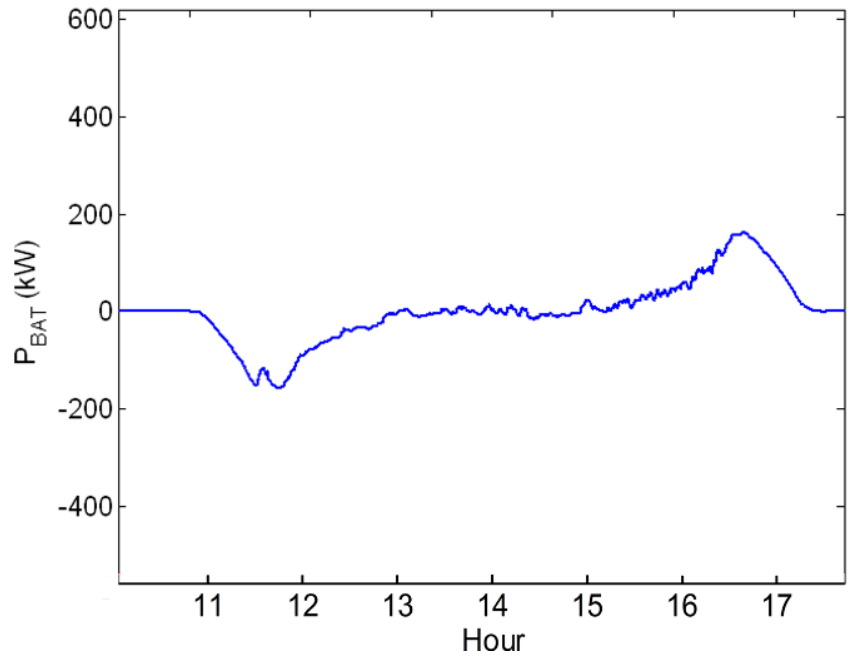

(b)

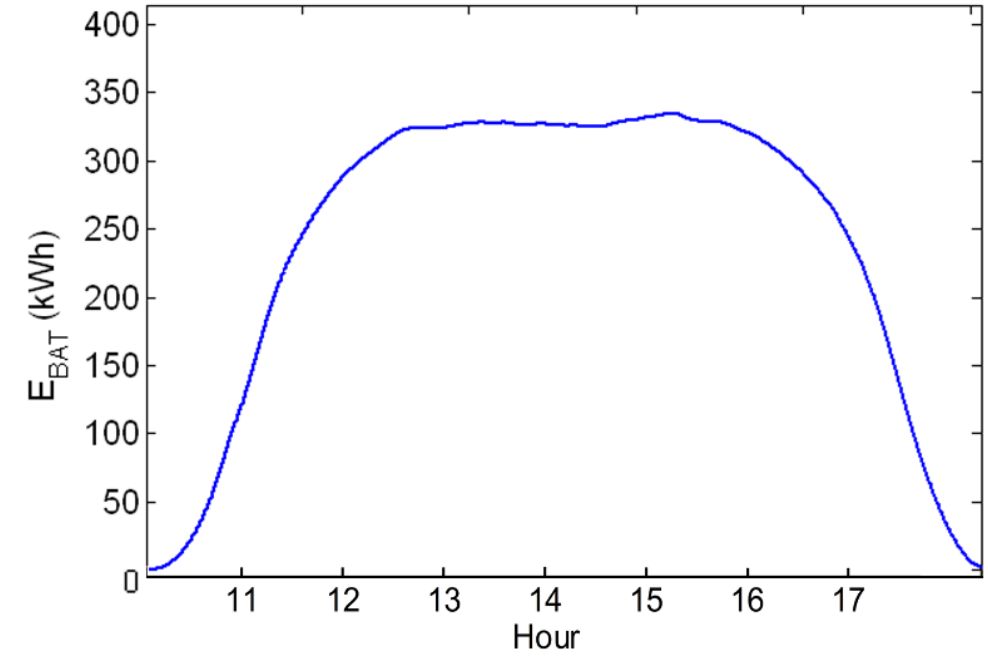

(c)

Selection of Time Window $T$ for the Moving-Average Strategy

Up to now, the $T$ value required to limit the fluctuations to below the $r_{\text {max }}$ limit is not known. This paper has provided an answer to this question. To do so, this strategy has been simulated for all the $5 \mathrm{~s}$ data over one year (2012) and for all the PV plant sections (0.55-38.5 MW). For a given value of $r_{\max }$ successive iterations were made, increasing the duration of $T$ (with a $60 \mathrm{~s}$ interval) until the condition $\left|\Delta P_{\Delta t}(t)\right|<r_{\max }$ was met. Figure 12 shows the relationship between the resulting time window $T$ and the maximum allowable ramp $r_{\text {max }}$, with the PV plant power output as a parameter. As can be seen, time window $T$ is solely dependent on $r_{\text {max }}$, and not on the size of the PV plant, $P^{*}$. That is the reason why in Figure 12 all the curves are superimposed. The evolution of these values, calls for making a fit based on function $T=m \cdot r_{\max }{ }^{-1}$, resulting in Equation (10): 


$$
T=\frac{5400}{r_{\max }}(s)
$$

where $r_{\max }$ is given in $(\% / \mathrm{min})$, and $m=5400(\mathrm{~s} \cdot \% / \mathrm{min})$. The goodness of fit $\left(R^{2}=0.99\right)$ confirms the validity of the Equation (10).

Figure 12. Relationship between the size of the power plant $P^{*}$, the maximum allowable ramp, $r_{\max }$ and window $T$, Equation (10).

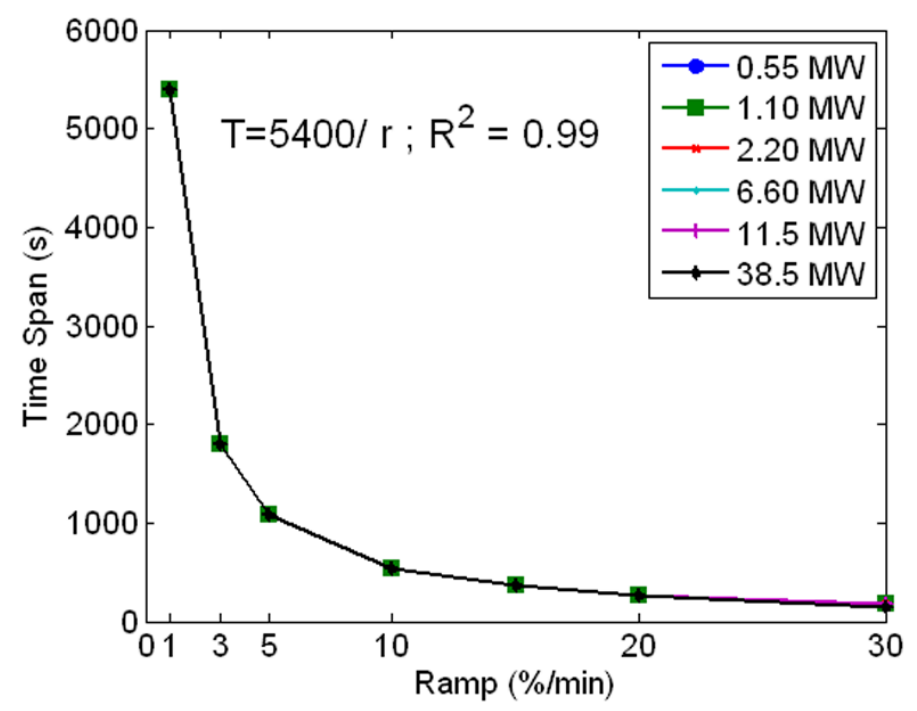

\subsection{Step-Rate Control Strategy}

Logically, the specifications required for the ESS are the direct consequence of the standards and regulations to be applied. For example, the reference [1] requires the smoothing of fluctuations of a very short duration, exceeding $10 \% / \mathrm{min}$. Translated to another time scale, variations of $100 \%$ in $10 \mathrm{~min}$ are permitted, being the typical fluctuations of a PV system with no energy storage provisions (for ranges of 1-40 MW) as seen in [15]. For this reason, based on the conclusions of this study, very small storage times are required, of around $6 \mathrm{~min}$. For other scenarios, such as [2], storage becomes more important: for a maximum ramp of $2 \% / \mathrm{min}$ (in other words $20 \%$ in $10 \mathrm{~min}$ ) the required storage time is increased by up to $45 \mathrm{~min}$ [15]. For these more severe constraints, it makes sense to try and seek strategies that optimize the ESS system. We shall now go on to propose an innovative step-rate control strategy based on strict compliance with the maximum ramp constraint $r_{\text {max }}$ for the defined time window (for example $10 \mathrm{~min}$ ). Hence, the proposed strategy attenuates the fluctuations in that particular time window and higher. Below that magnitude (high frequencies) we will take advantage of the geographical dispersion of a group of PV plants which strongly smoothens the fastest fluctuations. Previous studies $[8,31,32]$ have well proved that $N$ PV plants dispersed and separated at least by a few kilometers (6 km is enough) smoothens out the high frequencies (below $10 \mathrm{~min}$ ) proportionally with $\sqrt{ } N$. We understand $N$ to be sufficiently large to produce the necessary smoothing effect in order to mitigate the effect of these steps. Therefore, the step-control strategy is coherent in a scenario with a number $N$ of dispersed multi-MW PV-ESS plants, in which the step-control is implemented in each one, in the knowledge the TSO will see a reduction in the step effect simply due to geographical dispersion. Therefore, step control makes sense provided that the TSO permits strict compliance with $r_{\max }$ in the 
given time window. A detailed example of how this strategy works is shown in Figure 13, and it will be explained below.

Figure 13. Evolution of the generated power, $P \operatorname{Pv}(t)$ on 15 February 2012 by Section B (1.1 MW), the simulated power which would be injected to the grid $P_{\mathrm{G}}(t)$ in the case of the availability of a battery which limits fluctuations to $r_{\max }$ of $20 \% / 10 \mathrm{~min}$ using the step-control strategy $(n=120, n \cdot \Delta t=600 \mathrm{~s})$ and the ramp rate control. The reduction of the storage required compared to the ramp control is evident and corresponds to the area between $P_{\mathrm{G}, \text { ramp }}$ and $P_{\mathrm{G} \text {,step. }}$

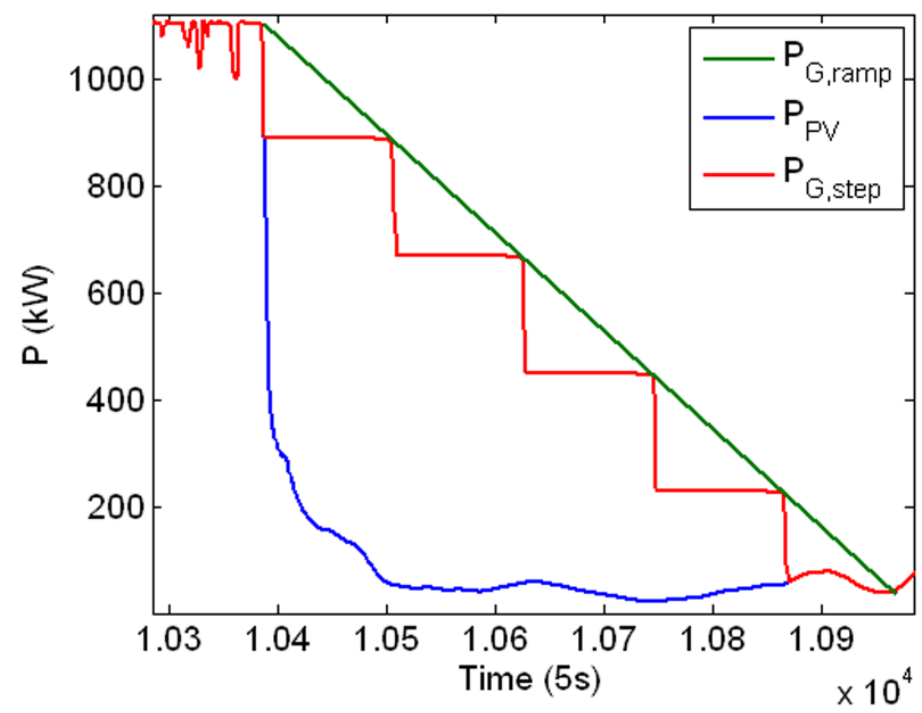

The algorithm of this strategy is as follows (Figure 14): the first step is to decide whether the present evolution of the PV generation is positive or negative. Then, a check is made to determine whether the ramp condition is met in a previous time window with a duration of $n$ times the sampling time $\Delta t$ ( $5 \mathrm{~s}$ in our case), in other words. This entails strict compliance with the ramp condition for times that are equal to or higher than $n \cdot \Delta t$, but not below this value.

Figure 14. Flowchart of the step-rate control.

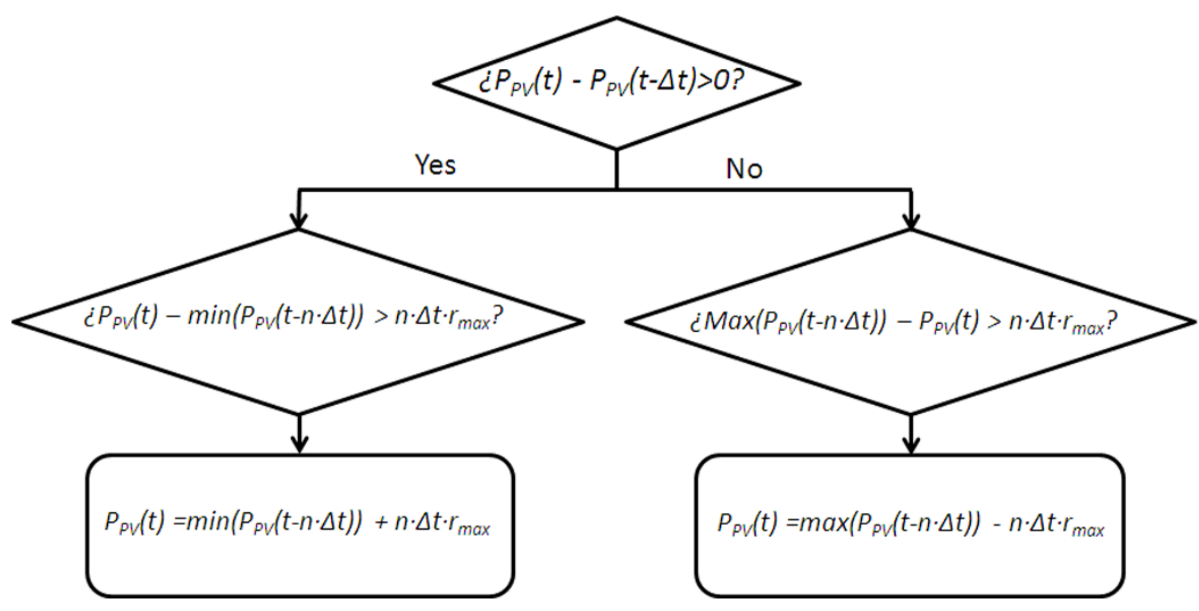

For example, for grid regulations evaluating the fluctuations every $10 \mathrm{~min}$, this would mean that the fluctuations would need to be below $r_{\max }=20 \% / 10 \mathrm{~min}$. For this case, it would be necessary to choose 
$n \cdot \Delta t=10 \min (n=120$ as $\Delta t$ is equal to $5 \mathrm{~s})$. Figure 13 shows the ramp control response $P_{\mathrm{G}, \text { ramp }}$ and that of the step-rate $P_{\mathrm{G} \text {,step }}$ for a negative fluctuation recorded on 15 February 2012 at 14:25:10 am. Before the significant negative fluctuation (during the first instant in Figure 13), short and small fluctuations (high-frequency) can be seen. These fluctuations are lower than $r_{\max }(2 \% / \mathrm{min})$ evaluated in $10 \mathrm{~min}(20 \%)$, so step-control does not act. However, when a negative fluctuation of around $90 \%$ takes place in $P_{\mathrm{PV}}$, step-control acts smoothing this fluctuation in $P_{\mathrm{G}}$ up to a $20 \%$ value. From an energetic point of view, thanks to the ESS, the power injected by the PV plant $P_{\mathrm{G}, \text { step }}$ evolved from $100 \%$ to $10 \%$ in $40 \mathrm{~min}$, similarly to ramp-rate control, $P_{\mathrm{G}, \text { ramp. The only difference between }}$ $P_{\mathrm{G}, \text { ramp }}$ and $P_{\mathrm{G} \text {,step }}$ are the steps, fast fluctuations below $10 \mathrm{~min}$. This high frequency will be strongly smoothed by geographical dispersion as it has been well proved in $[8,31,32]$, and then, going unnoticed for the TSO.

The area within $P_{\mathrm{G}, \text { ramp }}$ and $P_{\mathrm{G}, \text { step }}$ corresponds to the necessary battery reduction. Logically, the higher the $n \cdot \Delta t$ value, the less battery required. To prevent the constant battery discharge, this strategy also requires the same SOC control proposed for the ramp strategy (Figure 5).

Once more, determining the capacity needed by this strategy can be easy solved thanks to the worst fluctuation model (Figure 15). The energy saving for a power plant $P^{*}$ using the step-rate strategy instead of the ramp-rate, $E_{\text {step-ramp, }}(\mathrm{kW} \cdot \mathrm{h})$ is the integral of the difference between $P_{\mathrm{G}, \mathrm{ramp}}(t)$ and $P_{\mathrm{G}, \mathrm{ste}}(t)$, or, in other words, the total area of each of the triangles $N_{\text {tri }}$ of Figure 15 , in other words, Equation (11):

$$
E_{\text {step-ramp }}=\frac{1}{3600}\left[N_{\text {tri }} \cdot A_{\text {tri }}\right]=\frac{1}{3600}\left[\frac{90}{r_{\max }} \cdot \frac{1}{2}(n \cdot \Delta t) \frac{P^{*} r_{\max }}{100}\right]=\frac{0.45 P^{*}}{3600}(n \cdot \Delta t)
$$

where $P^{*}$ is expressed in $(\mathrm{kW})$, and $n \cdot \Delta t$ in $(\mathrm{s})$. For example, for $P^{*}=1.1 \mathrm{MW}(\tau=6.14 \mathrm{~s})$ and $r_{\max }=20 \% / 10 \mathrm{~min}$, Equation (3) gives $E_{\mathrm{BAT}, \mathrm{MAX}}=373 \mathrm{~kW} \cdot \mathrm{h}$. From Equation (11), with $n \cdot \Delta t=600 \mathrm{~s}$ the saving $E_{\text {step-ramp }}$ is equal to $82.5 \mathrm{~kW} \cdot \mathrm{h}$, that is $22 \%$. As can be observed, this percentage is independent of $r_{\max }$ and the PV plant size (or, in other words, $\tau$ ).

Figure 15. Model to calculate the storage capacity required for the worst fluctuation and step-rate strategy via $E_{\mathrm{BAT} \text {,ramp. }}$

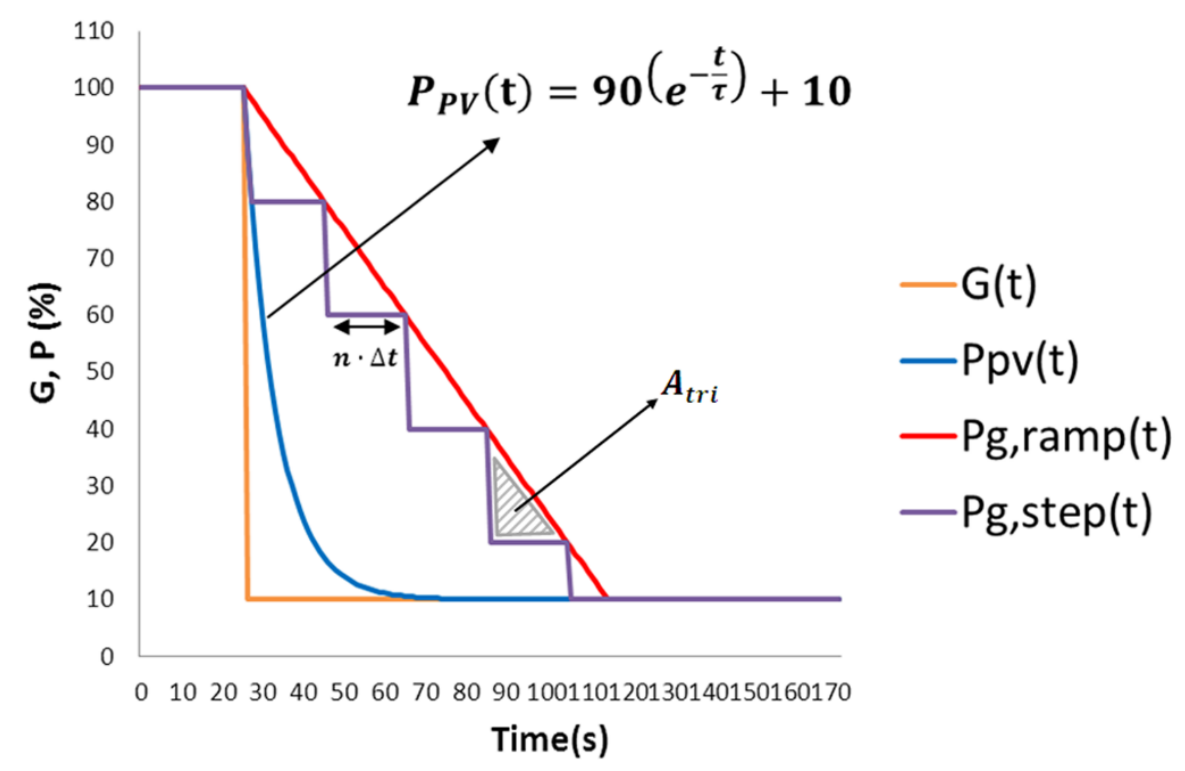


By way of example, Figure 16 again shows the results of simulating this strategy for 15 February and with $r_{\max }=20 \% / 10 \mathrm{~min}(2 \% / \mathrm{min})$. For this strategy and according to Equation (11), C $\mathrm{BAT}$ needed to smooth the worst fluctuation is equal to $582 \mathrm{~kW} \cdot \mathrm{h}$, so $E_{\mathrm{BAT}, \text { ref }}=291 \mathrm{~kW} \cdot \mathrm{h}$. For that given day, the required battery power is $P_{\mathrm{BAT}, \mathrm{MAX}}=879 \mathrm{~kW}$ (or $P_{\mathrm{BAT}, \mathrm{MAX}}=0.79 \cdot P^{*}$ ) and the required effective battery capacity is $C_{\mathrm{BAT}}=E_{\mathrm{BAT}, \mathrm{MAX}}-E_{\mathrm{BAT}, \mathrm{MIN}}=312 \mathrm{~kW} \cdot \mathrm{h}$ (or $17 \mathrm{~min}$ of storage equivalent to $0.28 \mathrm{~h}$ ). The total energy that has passed through the battery is $419 \mathrm{~kW} \cdot \mathrm{h}$, equivalent to $32 \%$ of daily production, whilst the total losses in the battery and PEC are $2.3 \%$. Obviously, $P_{\mathrm{G}}$ is more fluctuating than in the case of step-rate control, but the stress in the ESS and capacity needed are lower. The steps produced in $P_{\mathrm{G}}$ by this strategy can be better seen in Figure 13, which is precisely an enlarged version of Figure 16a.

Figure 16. (a) Evolution of the generated power, $P \operatorname{Pv}(t)$ on 15 February 2012 and the simulated power which would be injected to the grid $P_{\mathrm{G}}(t)$ under the step-rate strategy ( $n=120, n \cdot \Delta t=600 \mathrm{~s}$ ), limiting fluctuations to $r_{\max }$ of $20 \% / 10 \mathrm{~min}$; (b) battery power, $P_{\mathrm{BAT}}$; and (c) battery energy, $E_{B A T}$. The simulation has been made based on the model shown in Figure 5.

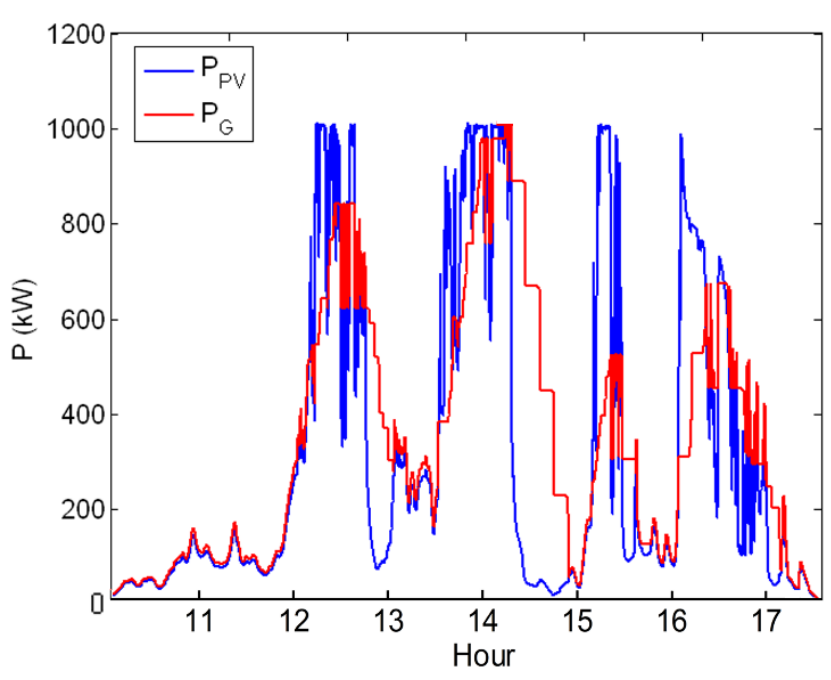

(a)

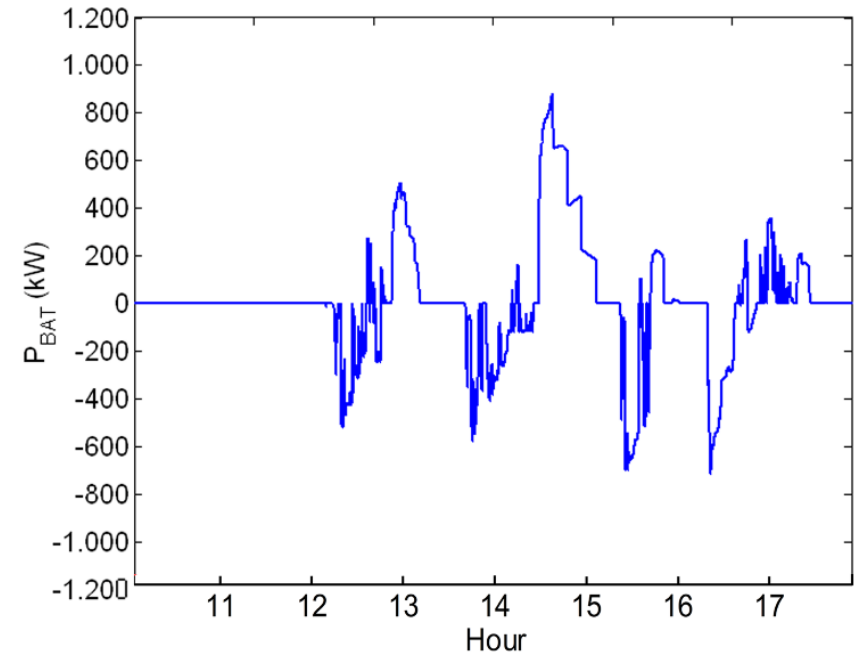

(b)

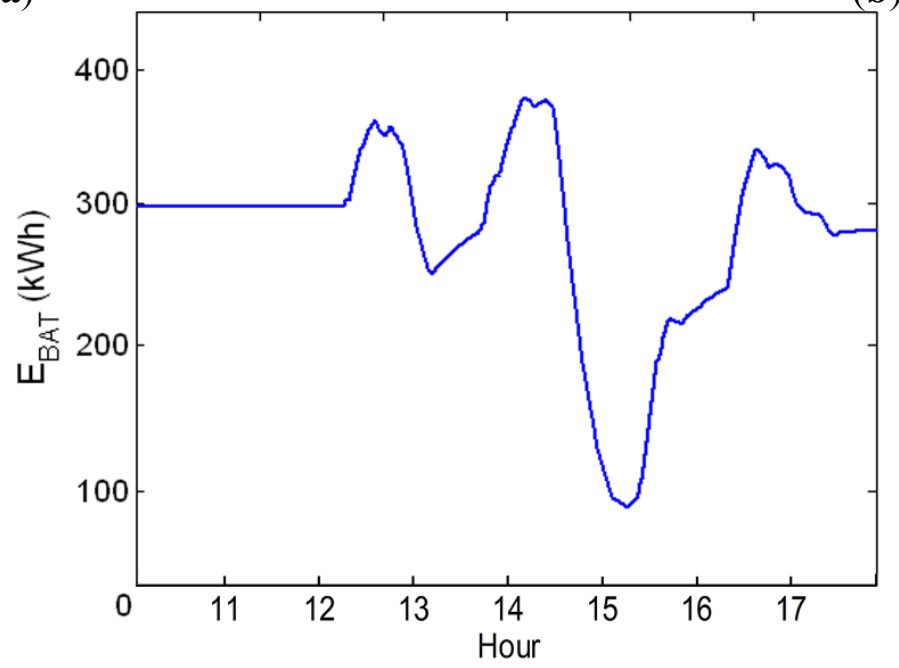

(c) 


\section{A Comparison of the Smoothing Strategies}

These three strategies were simulated for $5 \mathrm{~s}$ data for one year (2012) and for all the Amaraleja plant sections (from 0.55 MW to $38.5 \mathrm{MW}$ ), with a ramp restriction of $r_{\max }=2 \% / \mathrm{min}(20 \% / 10 \mathrm{~min}$ for the step-control), a similar restriction imposed by [2]. For the average moving strategy, this restriction requires a minimum $T$ of $2700 \mathrm{~s}$, according to Equation (10). For the step-rate control, $n=120$ $(120 \times 5 \mathrm{~s}=10 \mathrm{~min})$. It should be pointed out that the SOC was calculated on the effective storage capacity $C_{\mathrm{BAT}}$, thereby allowing $100 \%$ variations in the SOC (effective SOC). As a result of this, in the case of the ramp control and the step rate control, the reference SOC is 50\% whilst, for the moving average, the battery starts and ends each day fully discharged ( $\mathrm{SOC}=0 \%$ ). The indices of merit selected to compare the strategies are the effective storage time $t$ bat, the storage system losses, the degradation due to cycling and the quality of the wave injected into the grid.

\subsection{Effective Storage Time, $t_{\text {bat }}$}

The difference in the storage capacity required for the different strategies depends on the following factors: rated power output of the PV plant $P^{*}$ and maximum allowable ramp $r_{\text {max }}$. The first factor affects the dynamics of the power generated $P_{\mathrm{PV}}$, the greater the size of the PV plant, the greater the filtering in the power fluctuations [36]. Figure 17 shows the storage time required, $t_{\mathrm{BAT}}$, for each strategy, based on the size of the PV plant. This parameter was calculated after annual simulation, as the difference between the maximum and minimum annual energy value in the battery, $E_{\mathrm{BAT}, \mathrm{MAX}}-E_{\mathrm{BAT}, \mathrm{MIN}}$ divided between the rated power output $P^{*}$ of the PV system. Likewise, solid lines in Figure 17 shows the theoretical storage time calculated by Equations (4), (9) and (11) for each strategy.

Figure 17. Storage time required, $t_{\mathrm{BAT}}$, for each strategy, based on the size of the PV plant with a ramp restriction of $r_{\max }=2 \% / \mathrm{min}$. Solid lines show the theoretical storage time calculated by Equations (4), (9) and (11).

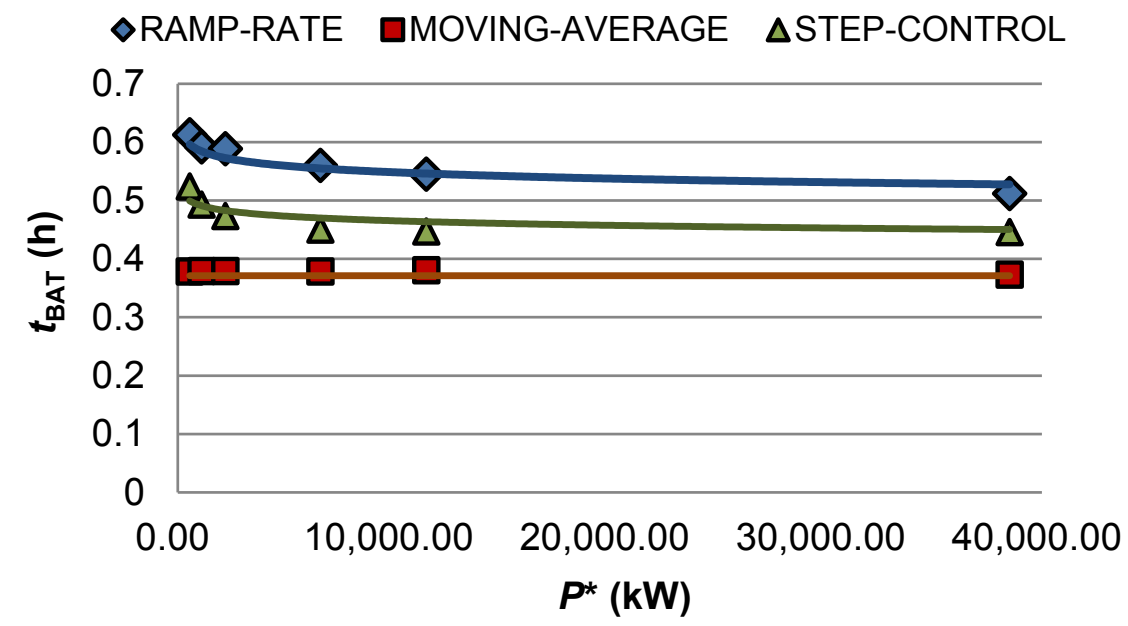

The step-rate control requires an average 20\% less storage than the ramp-rate control (the greater the value of parameter $n \cdot \Delta t$, the less battery required). Clearly, the MA strategy requires the smallest battery capacity. However, this strategy does not benefit from the fluctuation smoothing due to the size of the PV plant, as shown in Equation (3), unlike the ramp-rate and step-rate control strategies [15]. 
The best way to demonstrate this is Figure 18. It shows the relationship $C_{\mathrm{BAT}, \mathrm{ramp}} / C_{\mathrm{BAT}, \mathrm{MA}}$, constructed from Equations (4) and (9) for different values of $r_{\max }$ and $P^{*}$. As $r_{\max }$ and $P^{*}$ increases, $C_{\mathrm{BAT}, \mathrm{ramp}} / C_{\mathrm{BAT}, \mathrm{MA}}$ decreases. In any case, for restrictions around $2 \% / \mathrm{min}$, approximately half an hour of storage is sufficient to smooth the fluctuations.

Figure 18. Relation $C_{\mathrm{BAT}, \mathrm{ramp}} / C_{\mathrm{BAT}, \mathrm{MA}}$ based on the PV plant size $P^{*}$ and the maximum permitted ramp $r_{\text {max. }}$

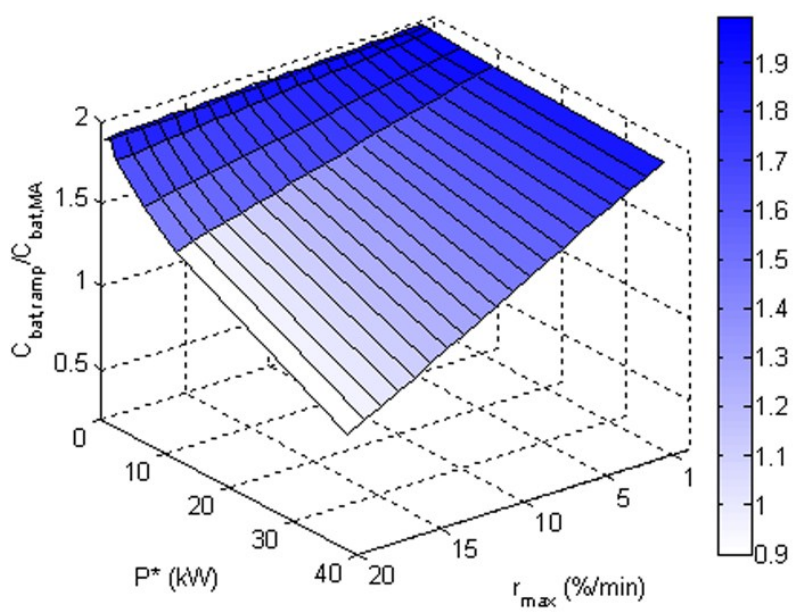

\subsection{Losses in the Storage System}

Figure 19a shows the total energy loss in the ESS (PEC and battery) for $r_{\max }=2 \% / \mathrm{min}$, expressed as a fraction of the annual production, based on the PV plant size. As can be seen, the losses for the moving average strategy are considerably higher than those for the other two strategies (2-3 times more). The reason lies in the fact that this strategy must act every day, regardless of whether there are any fluctuations or not, whilst the rate control strategies only act in the event of fluctuations greater than $r_{\text {max }}$. Figure $19 \mathrm{~b}$ shows again the losses but for a less stringent ramp, $r_{\max }=10 \% / \mathrm{min}$, as grid code in [1]. Moving average losses are considerably higher than for ramp-rate control. Note that in this new perspective, step-control would not proceed, because it allows fluctuations of 100\%/10 min. In any case, it should be highlighted that the losses are small for all strategies $(<1.4 \%$ in the worst case).

Figure 19. Losses at the PEC and battery, based on the size of the PV plant considered and the fluctuation smoothing strategy, with a ramp restriction of: (a) $r_{\max }=2 \% / \mathrm{min}$; and (b) $r_{\max }=10 \% / \mathrm{min}$.

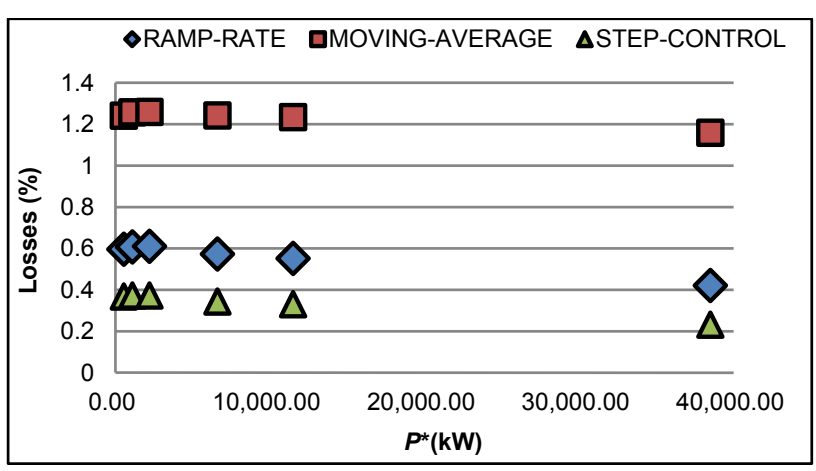

(a)

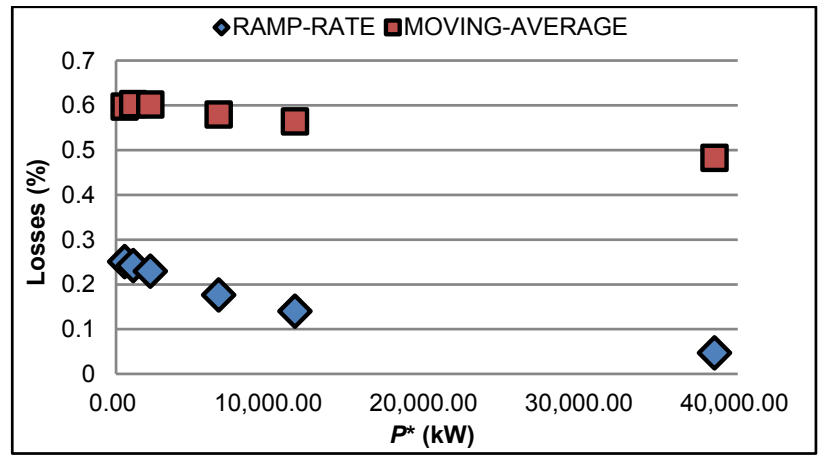

(b) 


\subsection{Stress in the Storage System}

Figure 20 shows the histogram for the annual effective SOC of the storage system for each of the strategies simulated in Section B (1.1 MW). As can be seen, the SOC distribution for the ramp-rate and step-rate strategies is very similar, being derived from the same algorithm: the control guarantees at all times that the effective SOC is maintained at around 50\%, only moving away from this reference value when significant fluctuations occur (charges and discharges to 50\%). These situations are extremely rare, consistent with the annual distribution of fluctuations already seen in [14]. However, the SOC distribution for the MA is clearly bimodal, and is quite different from the rate-control strategies. Each day the battery undergoes a complete charge-discharge cycle (100\% charge and discharge) with the maximum battery energy achieved at around midday, with full discharge at the end of the day, remaining in this state for the entire night. This explains the frequent SOC values close to $0 \%$ and $100 \%$.

Figure 20. Histogram for the effective SOC in the storage system resulting from the simulation of the ramp-rate, MA and step-rate strategies for $r_{\max }=2 \% / \mathrm{min}$. Note that the $y$-axis is logarithmically scaled.

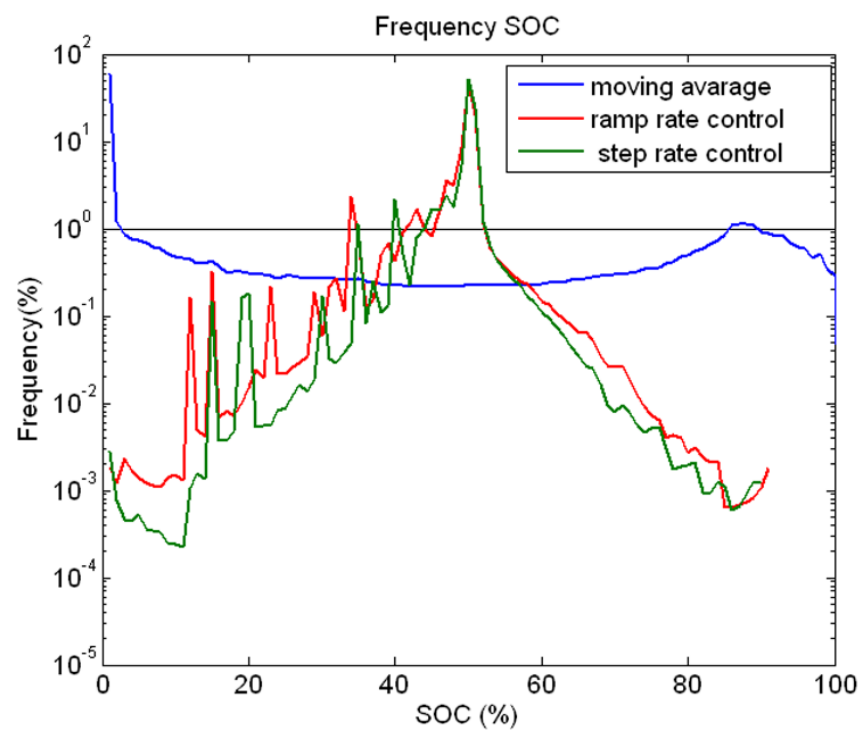

However, Figure 20 is insufficient to determine the extent of the storage system degradation due to cycling. This is largely dependent on the number of $N_{\text {cicl }}$ cycles and the depth of discharge (DOD). However, considering an annual effective SOC profile, such as those obtained in our simulations, there are methods to determine both parameters. One of the most-used algorithms and which provides the best results is Rainflow-counting [37]. Initially developed to calculate mechanical fatigue [36], this method has also proved to be equally valid for calculating the ESS ageing due to cycling [38-42]. In this way, any complex charging and discharging series can be broken down into a series of simple sub-cycles with a given $D O D$. The methodology followed in this document is similar to that shown in [39].

Figure 21 shows the result of applying the Rainflow-counting algorithm to the annual effective SOC for the various strategies and Section B (1.1 MW), for $r_{\max }=2 \% / \mathrm{min}$ and $10 \% / \mathrm{min}$. The figure shows the number of cycles $N_{\text {cicl }}$ occurring ( $y$ axis) and the DOD ( $x$ axis). For the moving average strategy the ESS performs more cycles and with depths of discharge which are practically double those of the other strategies. 
Figure 21. The number of observed cycles at a given depth of discharge $(D O D)$ for the strategies presented in this paper, for a maximum ramp limitation of: (a) $r_{\max }=2 \% / \mathrm{min}$ in Section B (1.1 MW); and (b) $r_{\max }=10 \% / \mathrm{min}$. Note that the $y$ axis is logarithmically scaled.

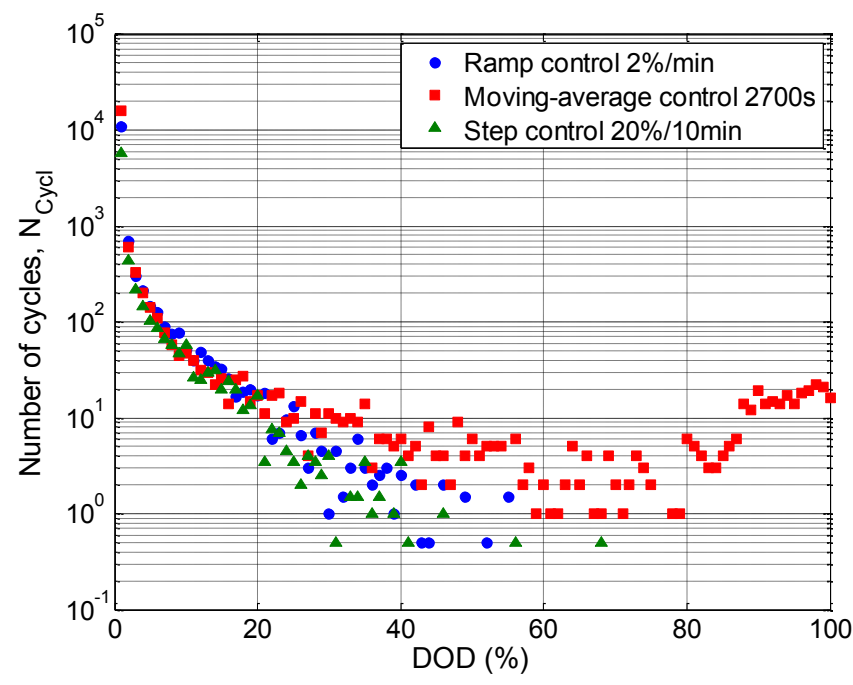

(a)

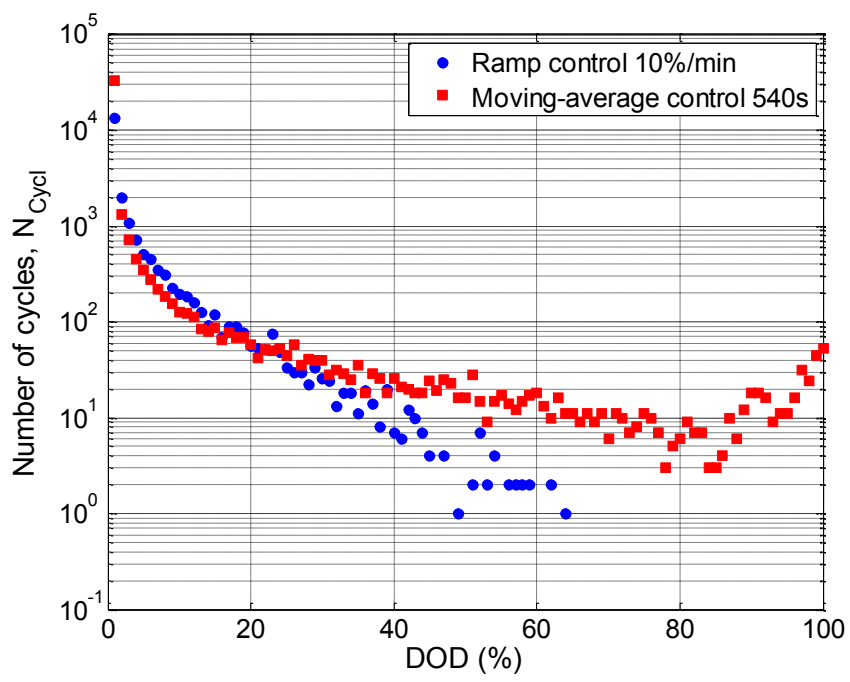

(b)

Once these curves have been obtained, the calculation of the annual degradation due to cycling is immediate. Assuming again that our ESS is a lithium ion battery, with a life cycle curve similar to that shown in Figure 22 [34]. This shows the number of maximum cycles $N_{\max }$ for a given $D O D$. It is possible to calculate the annual degradation due to cycling $C_{\mathrm{BAT} \text {,loss }}$ as the sum of each individual degradation to a given $D O D$, in other words the relationship between the number of annual cycles observed $N_{\text {cycl, }}$, and the number of maximum possible cycles $N_{\text {cycl,max }}$, is given in Equation (12):

$$
C_{\mathrm{BAT}, \mathrm{loss}}=\sum_{D O D=1}^{100} \frac{N_{\mathrm{cycl}, i}}{N_{\max , i}} \cdot 100 \quad(\%)
$$

Figure 22. Life cycle curve at $25^{\circ} \mathrm{C}, N_{\max } v s . D O D$, for a lithium ion battery made by SAFT. Reproduced with permission from [34]. Copyright (C) SAFT 2014.

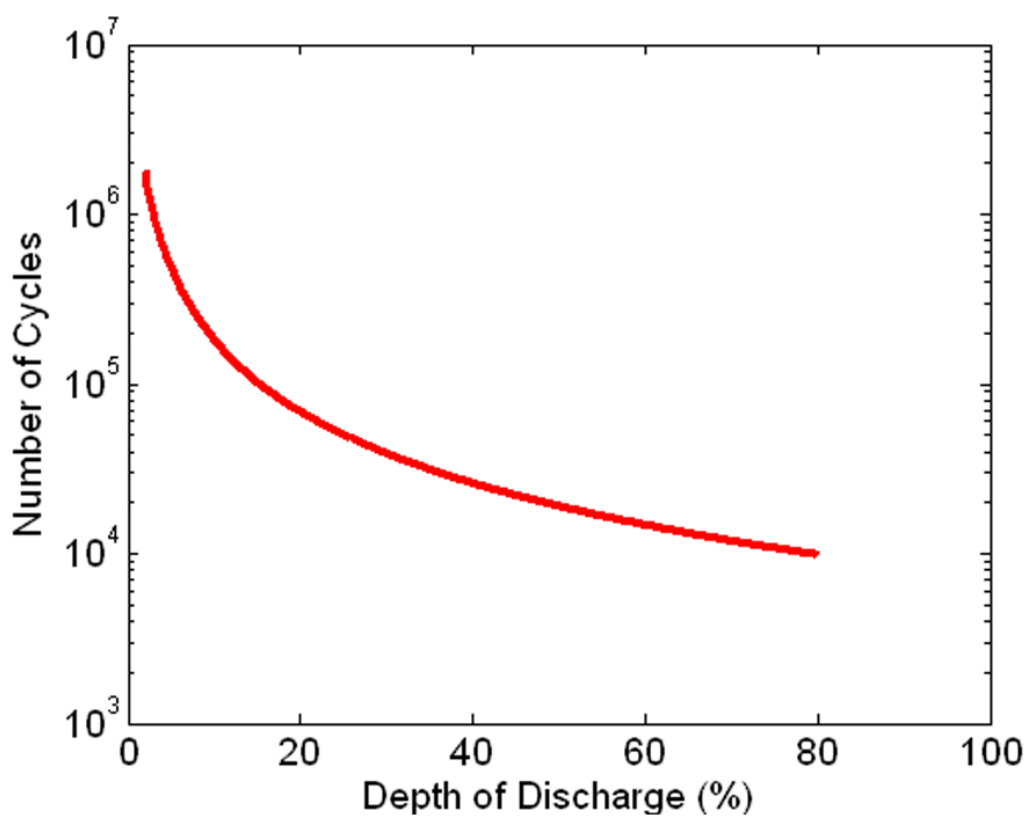


The results obtained by Equation (12) show the degradation solely due to the effect of the ESS cycling. However, additional effects exist which are not going to be taken into account and which affect service life, such as operating temperature. The method applied here for lithium batteries is also valid for any other storage technology, simply by knowing the ESS life cycle curve (Figure 23). The results of applying Equation (12) to the values of Figure $21 \mathrm{a}$ are equal to $1 \%, 11.09 \%$ and $0.6 \%$ for ramp-rate, MA and step-rate, respectively. Given the fact that the manufacturer does not permit $D O D$ values greater than $80 \%$, the data in Figure 21 a have been re-scaled to correspond to a $D O D$ of between $0 \%$ and $80 \%$.

This calculation methodology can be repeated for all the sections of the Amareleja plant observing the cycling degradation based on $P^{*}$ and the strategy considered (Figure 23a). The ramp-rate and step-rate control strategies show a very low cycling degradation $(0.5 \%-2 \%)$ which hardly affects the useful life of the battery, unlike the moving average strategy with a degradation of around 10 times greater. As can be seen, the step-control cycling degradation is in any case lower than that of the ramp-rate. Once more, as it has been done with the losses analysis, cycling degradation has been repeated for a less stringent restriction, $r_{\max }=10 \% / \min$ (Figure $23 \mathrm{~b}$ ). In this situation, capacity requirements $C_{\mathrm{BAT}}$, are lower, therefore cycling degradation is bigger than for $2 \% / \mathrm{min}$. Anyway, the difference between the strategies is similar to the ones showed for $r_{\max }=2 \% / \mathrm{min}$.

Figure 23. Annual degradation of the ESS due to cycling for: (a) $r_{\max }=2 \% / \mathrm{min}$; and (b) $r_{\max }=10 \% / \mathrm{min}$ for all strategies and based on the PV plant size.

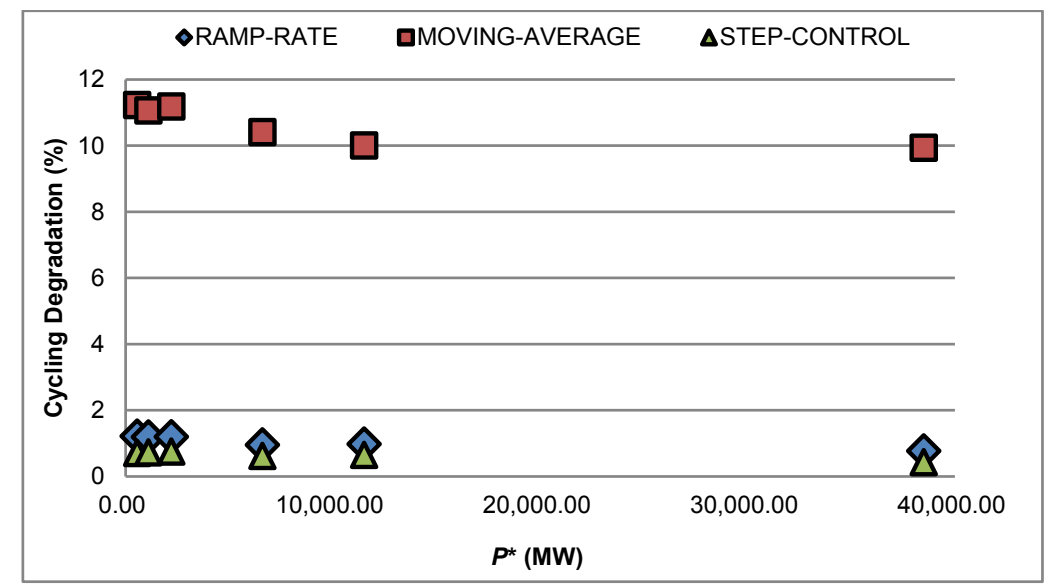

(a)

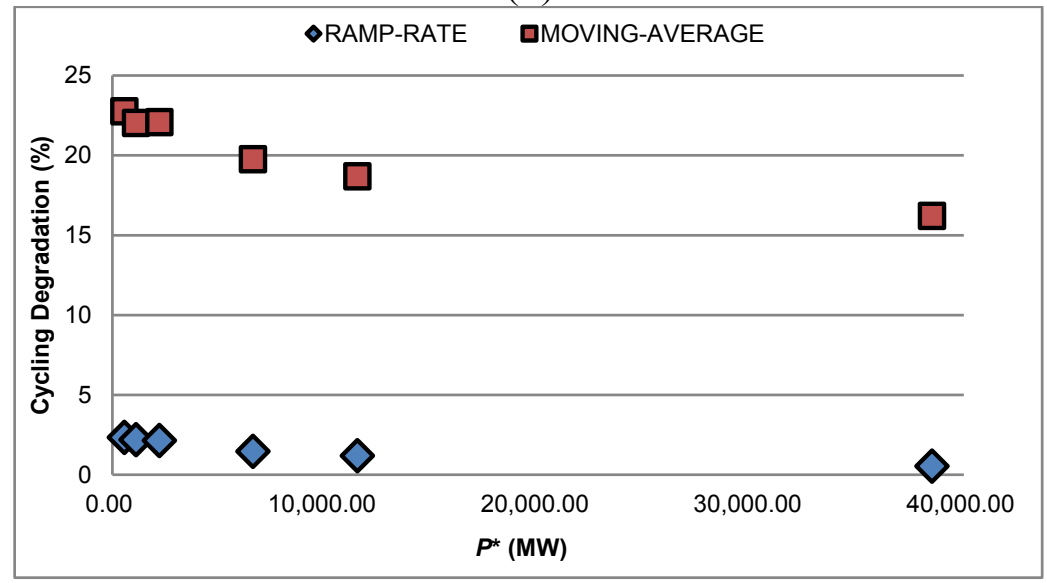

(b) 


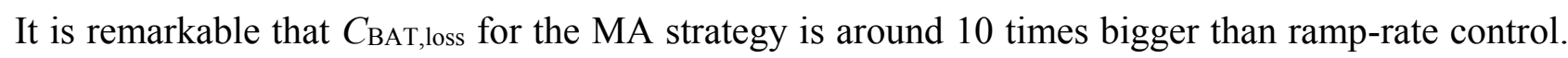
It could be argued that this comparison is not fair, because necessary $C_{\mathrm{BAT}}$ for the MA is, roughly speaking, the half respect ramp-rate control. Hence, $C_{\mathrm{BAT}}$, loss has been recalculated considering the same capacity

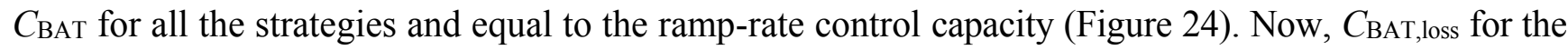
MA considerable decreases, but it still presents a degradation close to four times more than ramp-rate control $\left(3.6 \%\right.$ versus $1 \%$ for $r_{\max }=2 \% / \mathrm{min}$ and $\left.1.1 \mathrm{~kW}\right)$. This difference grows closer to $5-7$ times with respect to the step-control.

Figure 24. Annual degradation of the ESS due to cycling for: (a) $r_{\max }=2 \% / \mathrm{min}$; and (b) $r_{\max }=10 \% / \mathrm{min}$ for all strategies and based on the PV plant size assuming that all the strategies work with the $C_{\mathrm{BAT}}$ required for ramp-rate control.

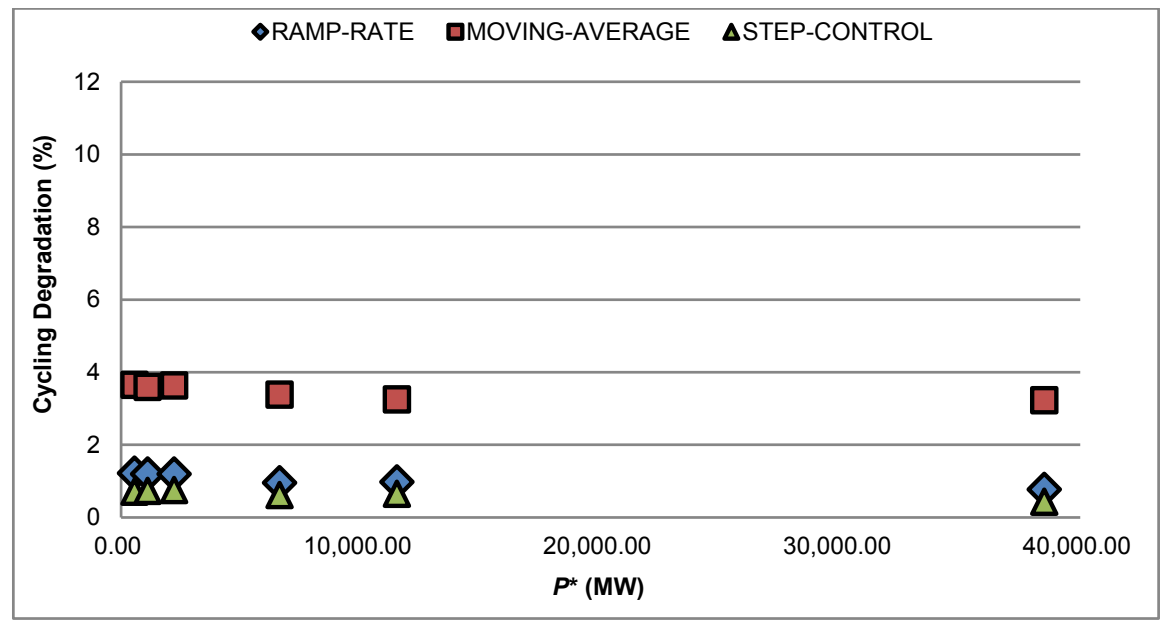

(a)

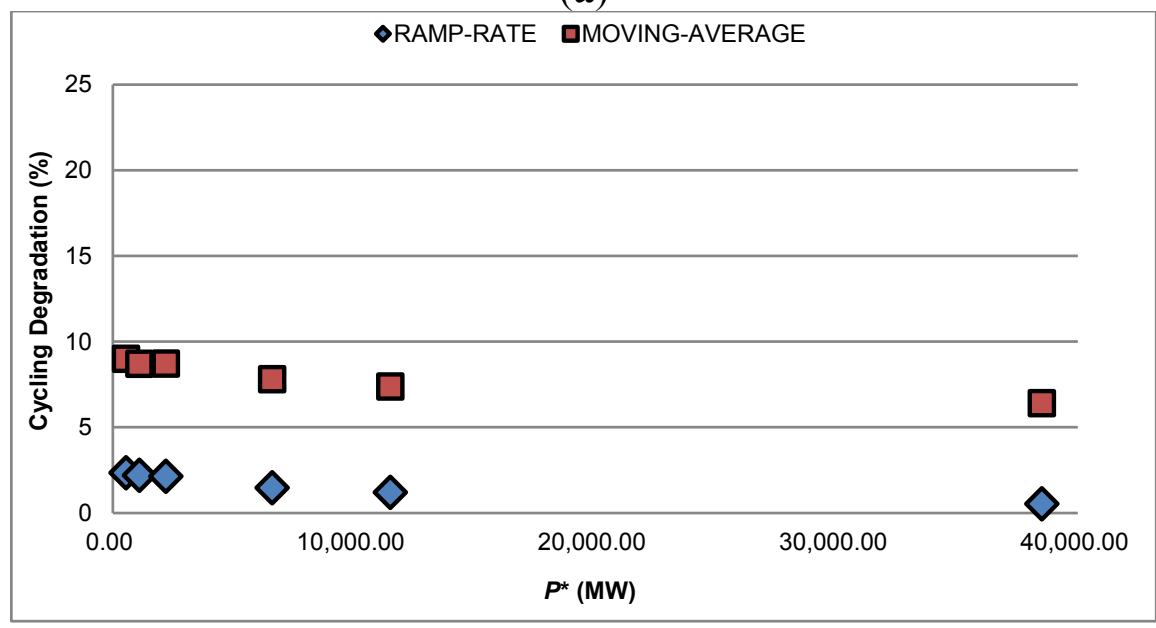

(b)

Recently, in order to avoid the daily MA cycling, Perez et al. [43] proposed to base the MA on the daily clear sky output ratio. Even so, it needs to resolve practical points such as control of the SOC (for example, how a midday negative fluctuation would be covered if the battery is discharged) or how to avoid constant discharge due to losses in the conversion elements. Likewise, it points out how forecasts can, to a large extent, help anticipate fluctuations and optimize the storage required and, in fact, the reference [43] discussed the improvement obtained with a perfect forecast, although how to face a situation in which the forecast fails has not been properly resolved. 


\subsection{Quality of the Signal Injected into the Grid}

Figure 25 shows $P_{\mathrm{G}}$ frequency spectrum for all the data for one year for Section B (1.1 MW) and for each of the strategies proposed in this article. The methodology followed is identical to that presented in $[44,45]$. Basically the method consists in applying the discrete Fourier transform (DFT) to variable $P_{\mathrm{G}}$ over an entire year, previously normalized (using $P^{*}$ ) computed by a fast Fourier transform (FFT) algorithm. As can be observed, the three strategies analyzed offer a similar cut-off filtering frequency of around $0.2 \mathrm{mHz}(1.4 \mathrm{~h})$, smoothing higher dynamics, particularly the MA strategy. However, it can be observed how the effect of the step-rate control filtering is reduced after frequencies close to $10 \mathrm{~min}(1.2 \mathrm{mHz})$, allowing faster dynamics to pass through and, therefore, injecting poorer quality power into the grid. However, this faster dynamics are easily reduced when we take in account the production of a PV fleet geographically dispersed, as it was demonstrated in $[5,31,32]$.

Figure 25. Spectrum for annual $P_{\mathrm{G}}$ resulting from the simulation of the three control strategies for the data for $P_{\mathrm{PV}}$ of Section B $\left(P^{*}=1.1 \mathrm{MW}\right)$.

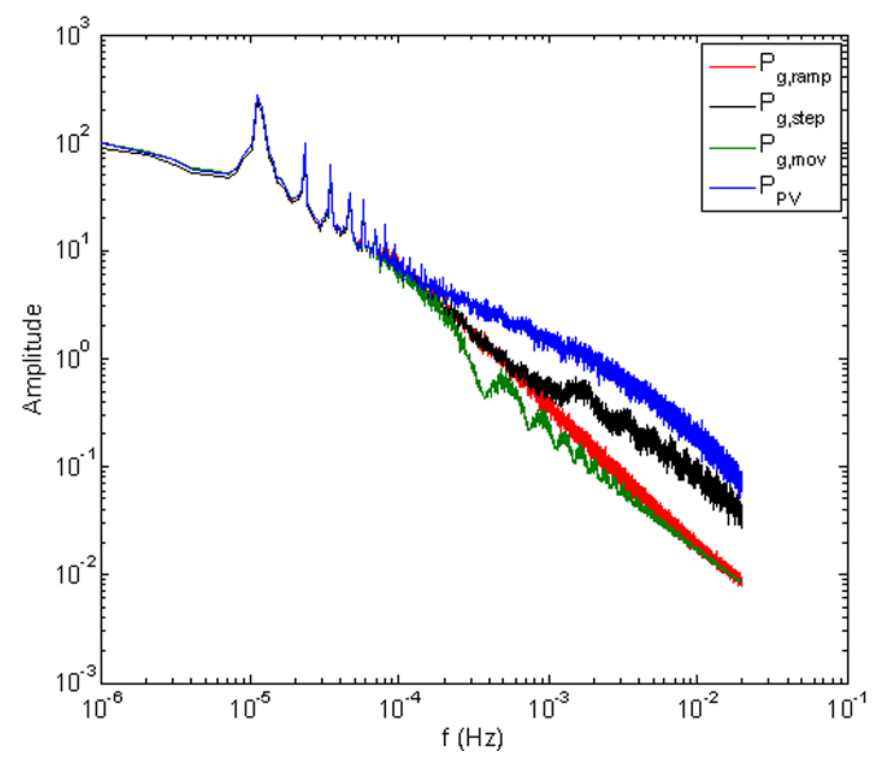

\section{Conclusions}

This paper has quantified the storage requirements needed to smooth short-term PV power fluctuations based on different control strategies and for a wide range of PV system power outputs. The one-year simulation of the strategies has demonstrated that the MA strategy requires the least storage capacity. However, it would be necessary to analyze in each particular case whether, firstly, this saving in size offsets the considerable increase in 2-3 times more of losses. Secondly, whether the storage technology is compatible with greater cycling (about 10 times more) and with SOC values close to zero for long periods of time. For example, for the case of lithium ion batteries, this strategy would have an extremely negative impact on the battery useful life, although this impact may be lower for ultra-capacitors or flow batteries. The new proposed strategy, namely the step-rate control, provides the most efficient use and with less ESS cycling in situations with several PV plants geographically dispersed and exigent ramp restrictions. Under less restrictive conditions, the ramp-rate 
control would be preferable against MA. Likewise, for a given grid restriction, an empirical expression is put forward to make it possible to determine the energy capacity required for each strategy.

We would highlight the lower losses achieved for the proposed system, particularly for the rate-control strategies (ageing due to cycling of around 1\%/year-2\%/year). This result draws attention to the potential use of the ESS for ancillary services (frequency regulation or time shifting), in an endeavor to maximize the value of its installation. To do so, a fluctuation prediction tool would be necessary, and this would need to be accurate enough to determine the critical times, in order to ensure the smart management of the energy stored.

\section{Acknowledgments}

The authors would like to thank Acciona for authorizing measurements at its PV plants and for their staff helpful collaboration. This work has been financed by the Seventh Framework Programme of the European Commission with the Project Photovoltaic Cost Reduction, Reliability, Operational Performance, Prediction and Simulation (PVCROPS—Grant Agreement No. 308468).

\section{Author Contributions}

The author Javier Marcos carried out the main research tasks and wrote the full manuscript, help in the simulation tasks by the author Iñigo de la Parra. Luis Marroyo supervised the results and Miguel García double-checked the whole manuscript.

\section{Conflicts of Interest}

The authors declare no conflict of interest.

\section{References}

1. PREPA Minimum Technical Requirements for Interconnection of Photovoltaic (PV) Facilities. Available online: http://www.fpsadvisorygroup.com/rso_request_for_quals/PREPA_Appendix_ E_PV_Minimum_Technical_Requirements.pdf (accessed on 6 March 2013).

2. CRE Reglas Generales de Interconexión al Sistema Eléctrico Nacional: Anexo 3: Requerimientos Técnicos para Interconexión de Centrales Solares Fotovoltaicas al Sistema Eléctrico Nacional. Available online: http://www.cre.gob.mx/documento/3025.pdf (accessed on 31 January 2014). (In Spanish)

3. National Energy Regulator of South Africa (NERSA). Grid Connection Code for Renewable Power Plants (RPPs) Connected to the Electricity Transmission System (TS) or the Distribution System (DS) in South Africa. Available online: http://www.nersa.org.za/Admin/Document/Editor/ file/Electricity/TechnicalStandards/South African Grid Code Requirements for Renewable Power Plants - Vesion 2 6.pdf (accessed on 31 January 2014).

4. Kuszamaul, S.; Ellis, A.; Stein, J.; Johnson, L. Lanai high-density irradiance sensor network for characterizing solar resource variability of MW-scale PV system. In Proceedings of the 2010 35th IEEE Photovoltaic Specialists Conference (PVSC), Honolulu, HI, USA, 20-25 June 2010; pp. 000283-000288. 
5. Otani, K.; Minowa, J.; Kurokawa, K. Study on areal solar irradiance for analyzing areally-totalized PV systems. Sol. Energy Mater. Sol. Cells 1997, 47, 281-288.

6. Woyte, A.; Belmans, R.; Nijs, J. Fluctuations in instantaneous clearness index: Analysis and statistics. Sol. Energy 2007, 81, 195-206.

7. Mills, A. Understanding Variability and Uncertainty of Photovoltaics for Integration with the Electric Power System; Lawrence Berkeley National Laboratory: Berkeley, CA, USA, 2010.

8. Lave, M.; Kleissl, J.; Arias-Castro, E. High-frequency irradiance fluctuations and geographic smoothing. Sol. Energy 2012, 86, 2190-2199.

9. Perez, R.; Hoff, T.E.; Schlemmer, J. Short-term irradiance variability: Station pair correlation as a function of distance. In Proceeding of the American Solar Energy Society (ASES) Annual Conference, Raleigh, NC, USA, 17-20 May 2011.

10. Wiemken, E.; Beyer, H.G.G.; Heydenreich, W.; Kiefer, K. Power characteristics of PV ensembles: Experiences from the combined power production of 100 grid connected PV systems distributed over the area of Germany. Sol. Energy 2001, 70, 513-518.

11. Curtright, A.; Apt, J. The character of power output from utility scale photovoltaic systems. Prog. Photovolt. Res. Appl. 2008, 16, 241-247.

12. Perpiñán, O.; Marcos, J.; Lorenzo, E. Electrical power fluctuations in a network of DC/AC inverters in a large PV plant: Relationship between correlation, distance and time scale. Sol. Energy 2013, 88, 227-241.

13. Mills, A.; Wiser, R. Implications of Wide-Area Geographic Diversity for Short-Term Variability of Solar Power; Lawrence Berkeley National Laboratory: Berkeley, CA, USA, 2010.

14. Marcos, J.; Marroyo, L.; Lorenzo, E.; Alvira, D.; Izco, E.; Ingeniería, D. Power output fluctuations in large scale PV plants: One year observations with one second resolution and a derived analytic model. Prog. Photovolt. Res. Appl. 2011, 19, 218-227.

15. Marcos, J.; Storkël, O.; Marroyo, L.; Garcia, M.; Lorenzo, E. Storage requirements for PV power ramp-rate control. Sol. Energy 2014, 99, 28-35.

16. Kakimoto, N.; Satoh, H.; Takayama, S.; Nakamura, K. Ramp-rate control of photovoltaic generator with electric double-layer capacitor. IEEE Trans. Energy Convers. 2009, 24, 465-473.

17. Khanh, L.N.; Seo, J.-J.; Kim, Y.-S.; Won, D.-J. Power-management strategies for a grid-connected PV-FC hybrid system. IEEE Trans. Power Deliv. 2010, 25, 1874-1882.

18. Yan, R.; Saha, T.K. Power ramp rate control for grid connected photovoltaic system. In Proceedings of the 2010 IPEC Conference, Singapore, 27-29 October 2010; pp. 83-88.

19. Wang, L.; Lin, Y.-H.; Wang, L. Random fluctuations on dynamic stability of a grid-connected photovoltaic array. In Proceedings of the 2001 IEEE Power Engineering Society Winter Meeting, Columbus, OH, USA, 28 January-1 February 2001; Volume 3, pp. 985-989.

20. Li, X.; Hui, D.; Lai, X. Battery energy storage station (BESS)-based smoothing control of photovoltaic (PV) and wind power generation fluctuations. IEEE Trans. Sustain. Energy 2013, 4, 464-473.

21. Alam, M.; Muttaqi, K.; Sutanto, D. A novel approach for ramp-rate control of solar PV using energy storage to mitigate output fluctuations caused by cloud passing. IEEE Trans. Energy Convers. 2014, 29, 507-518. 
22. Datta, M.; Senjyu, T.; Yona, A.; Funabashi, T.; Kim, C.-H. Photovoltaic output power fluctuations smoothing methods for single and multiple PV generators. Curr. Appl. Phys. 2010, $10, \mathrm{~S} 265-\mathrm{S} 270$.

23. Seo, H.-R.; Kim, G.-H.; Kim, S.-Y.; Kim, N.; Lee, H.-G.; Hwang, C.; Park, M.; Yu, I.-K. Power quality control strategy for grid-connected renewable energy sources using PV array and supercapacitor. In Proceedings of the 2010 International Conference on Electrical Machines and Systems (ICEMS), Incheon, Korea, 10-13 October 2010; pp. 437-441.

24. Chanhom, P.; Sirisukprasert, S.; Hatti, N. A new mitigation strategy for photovoltaic power fluctuation using the hierarchical simple moving average. In Proceedings of the 2013 IEEE International Workshop on Intelligent Energy Systems (IWIES), Vienna, Austria, 14 November 2013; pp. 28-33.

25. Han, X.; Chen, F.; Cui, X.; Li, Y.; Li, X. A power smoothing control strategy and optimized allocation of battery capacity based on hybrid storage energy technology. Energies 2012, 5, 1593-1612.

26. Beltran, H.; Bilbao, E.; Belenguer, E.; Etxeberria-Otadui, I.; Rodriguez, P. Evaluation of storage energy requirements for constant production in PV power plants. IEEE Trans. Ind. Electron. 2013, 60, 1225-1234.

27. Darras, C.; Muselli, M.; Poggi, P.; Voyant, C.; Hoguet, J.-C.; Montignac, F. PV output power fluctuations smoothing: The MYRTE platform experience. Int. J. Hydrog. Energy 2012, 37, 14015-14025.

28. Nuhic, A.; Terzimehic, T.; Soczka-Guth, T.; Buchholz, M.; Dietmayer, K. Health diagnosis and remaining useful life prognostics of lithium-ion batteries using data-driven methods. J. Power Sources 2013, 239, 680-688.

29. Beltran, H.; Swierczynski, M.; Luna, A.; Vazquez, G.; Belenguer, E. Photovoltaic plants generation improvement using Li-ion batteries as energy buffer. In Proceedings of the 2011 IEEE International Symposium on Industrial Electronics (ISIE), Gdansk, Poland, 27-30 June 2011; pp. 2063-2069.

30. Cheng, F.; Willard, S.; Hawkins, J.; Arellano, B.; Lavrova, O.; Mammoli, A. Applying battery energy storage to enhance the benefits of photovoltaics. In Proceedings of the 2012 IEEE Energytech, Cleveland, OH, USA, 29-31 May 2012; pp. 1-5.

31. Marcos, J.; Marroyo, L.; Lorenzo, E.; García, M. Smoothing of PV power fluctuations by geographical dispersion. Prog. Photovolt. Res. Appl. 2012, 20, 226-237.

32. Hoff, T.E.; Perez, R. Quantifying PV power output Variability. Sol. Energy 2010, 84, 1782-1793.

33. Ingeteam. INGECON SUN POWERMAX $(275-1070 \mathrm{~kW})$. Available online: http://www.ingeteam.com/es-es/energia/energia-fotovoltaica/p15_24_36/ingecon-sun-powermax.aspx (accessed on 14 October 2014).

34. SAFT SA. Intensium ${ }^{\circledR}$ Flex, Product Brochure, 2008. Available online: http://www.saftbatteries.com/battery-search/intensium\%C2\%AE-flex (accessed on 31 January 2014).

35. Downing, S.D.; Socie, D.F. Simple rainflow counting algorithms. Int. J. Fatigue 1982, 4, 31-40.

36. Hund, T.D.; Gonzalez, S.; Barrett, K. Grid-tied PV system energy smoothing. In Proceedings of the 2010 35th IEEE Photovoltaic Specialists Conference (PVSC), Honolulu, HI, USA, 20-25 June 2010; pp. 002762-002766. 
37. Matsuishi, M.; Endo, T. Fatigue of metals subjected to varying stress. Jpn. Soc. Mech. Eng. 1968, 96, 37-40.

38. Dufo-López, R.; Bernal-Agustín, J.L.; Contreras, J. Optimization of control strategies for stand-alone renewable energy systems with hydrogen storage. Renew. Energy 2007, 32, 1102-1126.

39. Dufo-López, R.; Lujano-Rojas, J.M.; Bernal-Agustín, J.L. Comparison of different lead-acid battery lifetime prediction models for use in simulation of stand-alone photovoltaic systems. Appl. Energy 2014, 115, 242-253.

40. Datta, M.; Senjyu, T.; Yona, A.; Funabashi, T. Photovoltaic output power fluctuations smoothing by selecting optimal capacity of battery for a photovoltaic-diesel hybrid system. Electr. Power Compon. Syst. 2011, 39, 621-644.

41. Gee, A.M.; Robinson, F.V.P.; Dunn, R.W. Analysis of battery lifetime extension in a small-scale wind-energy system using supercapacitors. IEEE Trans. Energy Convers. 2013, 28, 24-33.

42. Schaltz, E.; Khaligh, A.; Rasmussen, P.O. Influence of battery/ultracapacitor energy-storage sizing on battery lifetime in a fuel cell hybrid electric vehicle. IEEE Trans. Veh. Technol. 2009, 58, 3882-3891.

43. Perez, R.; Kivalov, S.; Hoff, T.E.; Dise, J.; Chalmers, D. Mitigating short-term PV output intermittency. In Proceedings of the 28th European Photovoltaic Solar Energy Conference and Exhibition (EU PVSEC), Villepinte, France, 30 September-4 October 2013; pp. 3719-3726.

44. Marcos, J.; Marroyo, L.; Lorenzo, E.; Alvira, D.; Izco, E. From irradiance to output power fluctuations: The PV plant as a low pass filter. Prog. Photovolt. Res. Appl. 2011, 19, 505-510.

45. Apt, J. The spectrum of power from wind turbines. J. Power Sources 2007, 169, 369-374.

(C) 2014 by the authors; licensee MDPI, Basel, Switzerland. This article is an open access article distributed under the terms and conditions of the Creative Commons Attribution license (http://creativecommons.org/licenses/by/4.0/). 